UNIVERSIDADE DE BRASÍLIA

FACULDADE DE CIÊNCIAS DA SAÚDE

PROGRAMA DE PÓS-GRADUAÇÃO EM CIÊNCIAS DA SAÚDE

\author{
AMILTON VIEIRA
}

\title{
EFEITO DA TEMPERATURA DA ÁGUA DURANTE IMERSÃO EM ÁGUA GELADA NA RECUPERAÇÃO DO DANO MUSCULAR INDUZIDO PELO EXERCÍCIO
}

Tese apresentada como requisito parcial para a obtenção do Título de Doutor em Ciências da Saúde pelo Programa de Pós-Graduação em Ciências da Saúde da Universidade de Brasilia.

Orientador: Martim Francisco Bottaro Marques

BRASÍLIA

2016 


\title{
AMILTON VIEIRA
}

\section{EFEITO DA TEMPERATURA DA ÁGUA DURANTE IMERSÃO EM ÁGUA GELADA NA RECUPERAÇÃO DO DANO MUSCULAR INDUZIDO PELO EXERCÍCIO}

Tese apresentada como requisito parcial para a obtenção do Título de Doutor em Ciências da Saúde pelo Programa de Pós-Graduação em Ciências da Saúde da Universidade de Brasilia.

Aprovado em 24 de Junho de 2016

\section{BANCA EXAMINADORA}

\author{
Martim Francisco Bottaro Marques - (presidente) \\ Universidade de Brasília \\ Cláudio Alexandre Gobatto \\ Universidade Estadual de Campinas
}

Ricardo Jacó de Oliveira

Universidade de Brasília

João Luiz Quaglioti Durigan

Universidade de Brasília

João Batista Ferreira Junior

Instituto Federal de Educação Ciências e Tecnologia do Sudeste de Minas Gerais 


\section{RESUMO}

Introdução: A imersão em água gelada (IAG) com temperaturas variando de 5 a $15 \stackrel{\circ}{\circ} \mathrm{C}$ vem sendo frequentemente utilizada no tratamento dos sinais e sintomas do dano muscular induzidos pelo exercício (DMIE). No entanto, até o momento não existe um consenso da temperatura ideal na recuperação do DMIE. Objetivo: O objetivo do presente estudo foi investigar os efeitos de diferentes temperaturas de IAG (i.e., $5 \stackrel{\circ}{\circ} \mathrm{C}$ e $\left.15{ }^{\circ} \mathrm{C}\right)$ na recuperação do DMIE. Métodos: Quarenta e dois homens universitários realizaram cinco séries de 20 repetições de salto em profundidade 'drop jump' e foram aleatóriamente alocados em um dos três grupos experimentais: 1) IAG a $5{ }^{\circ} \mathrm{C}$ (G5, $\mathrm{n}=$ 14); 2) IAG a $15 \stackrel{\circ}{ } \mathrm{C}(\mathrm{G} 15, \mathrm{n}=14)$; ou 3 ) controle ( $\mathrm{GC}, \mathrm{n}=14)$. Após o exercício, os indivíduos dos grupos IAG tiveram seus membros inferiores imersos em água gelada por $20 \mathrm{~min}$, enquanto que aqueles do GC permaneceram sentados pelo mesmo período de tempo sem IAG. Força isométrica dos extensores do joelho, salto com contramovimento (SCM), dor muscular de início tardio (DMIT), e creatina quinase (CK) foram mensurados antes (pré) e ao longo de uma semana após o exercício. Resultados: Não houve diferença entre os grupos na recuperação da força isométrica $(p=0.73)$. No entanto, G5 e G15 recuperaram o desempenho do SCM mais rapidamente que o GC ( $p<0.05)$. O desempenho do SCM retornou aos níveis pré-exercício após 72h para G15, após 96h para G5, enquanto que o GC não recuperou em nenhum dos momentos avaliados. Além disso, $\mathrm{CK}$ retornou aos níveis basais em $72 \mathrm{~h}$ e assim permaneceu nos demais momentos para o G15, enquanto que em ambos G5 e GC os níveis permaneceram elevados por pelo menos $168 \mathrm{~h}$. Houve uma tendência para uma menor DMIT ( $p=0.06)$ no G15 quando comparado com GC 24h após o exercício. Conclusão: IAG acelerou a recuperação do desempenho do SCM, mas não a recuperação da força isométrica. Este resultado sugere que IAG possa promover a recuperação do desempenho em atividades que envolvam o ciclo alongamento-encurtamento. Porém, parece não influenciar na recuperação da força máxima contrátil. Adicionalmente, a imersão em água muito gelada como a $5 \stackrel{\circ}{\mathrm{C}}$ não parece ser tão efetiva quanto em águas menos geladas $\left(15^{\circ} \mathrm{C}\right)$ em promover recuperação ao exercício estenuante. 
Palavras-Chave: crioterapia; função muscular; torque extensor do joelho; salto vertical; dor muscular de início tardio; creatina quinase 


\section{ABSTRACT}

Introduction: Although cold water immersion (CWI) is often used to treat sign and symptoms of exercise-induced muscle damage (EIMD), the water temperature has been poorly controlled. Purpose: The purpose of the present study was to investigate the effects of $5^{\circ} \mathrm{C}$ and $15^{\circ} \mathrm{C} \mathrm{CWI}$ on recovery from exercise resulting in EIMD. Methods: Forty-two college-aged men performed five sets of 20 drop jumps and were randomly allocated into one of three groups: 1$) \mathrm{CWI}$ at $5^{\circ} \mathrm{C}(\mathrm{G} 5, \mathrm{n}=14)$; 2$) \mathrm{CWI}$ at $15^{\circ} \mathrm{C}(\mathrm{G} 15, \mathrm{n}=$ $14)$; or 3 ) control ( $C G, n=14)$. After exercise, individuals from the $C W I$ groups had their lower limbs immerged in iced water for $20 \mathrm{~min}$, whereas those from the CG remained seated for the same period of time without CWI. Isometric knee extensor torque, countermovement jump (CMJ), delayed-onset muscle soreness (DOMS), and creatine kinase (CK) were measured before (pre) along one week period post exercise. Results: There was no between-group difference in isometric strength recovery $(p=0.73)$. However, CMJ recovered quicker in $G 5$ and $G 15$ compared to $C G(p<0.05)$. CMJ returned to baseline after $72 \mathrm{~h}$ for $\mathrm{G} 15$, G5 recovered after $96 \mathrm{~h}$ and GC did not recovered at any time point measured. Also, CK returned to baseline at $72 \mathrm{~h}$ and remained stable for all remaining measurements for $\mathrm{G} 15$, whereas $\mathrm{CK}$ in both $\mathrm{G} 5$ and $\mathrm{GC}$ remained elevated past $168 \mathrm{~h}$. There was a trend toward lower DOMS ( $p=0.06)$ in $\mathrm{G} 15$ when compared to CG at $24 \mathrm{~h}$ post-exercise. Conclusions: $\mathrm{CWI}$ accelerated CMJ performance, but not isometric strength recovery. The result suggests that $\mathrm{CWI}$ might promote recovery of stretchshortening cycle performance, but may not influence the recovery of maximal contractile force. Additionally, immersion at warmer temperature may be more effective than colder temperatures promoting recovery from strenuous exercise.

Keywords: cryotherapy; muscle function; knee extensor torque; vertical jump; delayedonset muscle damage; creatine kinase; 


\section{LISTA DE FIGURAS}

Figura 1. Sessão de crioterapia de imersão em água gelada para Página 18 membros inferiores.

Figura 2. Delineamento experimental do estudo.

Página 28

Figura 3. Recuperação da força muscular após dano muscular induzido pelo exercício nos diferentes grupos experimentais.

Página 34

Figura 5. Comportamento da dor muscular de início tardio após dano muscular induzido pelo exercício nos diferentes grupos experimentais.

Figura 6. Cinética da concentração sérica de creatina quinase após dano muscular induzido pelo exercício nos diferentes grupos experimentais.

Figura 7. Efeito da imersão em água gelada sobre a temperatura da pele, conforto térmico, e sensação térmica nos diferentes grupos experimentais.

Página 36

Página 37

Página 38 


\section{LISTA DE TABELAS}

Tabela 1. Estudos investigando o efeito da imersão em água Página 21 gelada na recuperação do desempenho muscular

Tabela 2. Características físicas basais dos participantes do estudo Página 27 


\section{LISTA DE ABREVIATURAS E SIGLAS}

\begin{tabular}{|c|c|}
\hline$\%$ & Percentual \\
\hline${ }^{\circ} \mathbf{C}$ & Graus Celsius \\
\hline$\mu \mathrm{L}$ & Microlítro \\
\hline ANOVA & Análise de Variância \\
\hline CAE & Ciclo alongamento-encurtamento \\
\hline CK & Creatina Quinase \\
\hline $\mathbf{c m}$ & Centímetros \\
\hline CVM & Contração Voluntária Máxima \\
\hline DMIE & Dano Muscular Induzido pelo Exercício \\
\hline DMIT & Dor Muscular de Início Tardio \\
\hline EMG & Atividade Neuromuscular \\
\hline EPM & Erro Padrão da Média \\
\hline$f$ & Tamanho do Efeito \\
\hline G15 & Grupo $15^{\circ} \mathrm{C}$ \\
\hline G5 & Grupo $5 \stackrel{\circ}{\mathrm{C}}$ \\
\hline GC & Grupo Controle \\
\hline $\mathbf{h}$ & Horas \\
\hline HIT & Exercício Intervalado de Alta Intensidade \\
\hline IAG & Imersão em Água Gelada \\
\hline kg & Kilogramas \\
\hline $\min$ & Minutos \\
\hline $\mathbf{m m}$ & Milímetros \\
\hline MMII & Membros Inferiores \\
\hline MMSS & Membros Superiores \\
\hline N.m & Newton Metros \\
\hline p & Probabilidade \\
\hline
\end{tabular}

PAR-Q Questionário de Prontidão para Atividades Físicas rpm Rotações por Minuto 
SCM Salto com Contramovimento

SPSS Statistical Package for Social Sciences

vVO2max Velocidade no Consumo Máximo de Oxigênio 


\section{SUMÁRIO}

1 INTRODUÇÃO 12

2 OBJETIVOS $\quad 14$

3 REVISÃO DE LITERATURA 15

3.1 Mecanismos envolvidos na crioterapia 16

$\begin{array}{lll}3.2 & \text { Crioterapia de imersão em água gelada } & 18\end{array}$

3.3 Efeito agudo da imersão em água gelada no desempenho 19 neuromuscular

3.4 Efeito da imersão em água gelada na recuperação muscular 20

3.5 Efeito da imersão em água gelada na dor muscular de início tardio 23

3.6 Efeito da imersão em água gelada na concentração sanguínea de 24 creatina quinase

4 MÉTODOS 26

$\begin{array}{lll}4.1 & \text { Participantes } & 26\end{array}$

$\begin{array}{lll}4.2 & \text { Delineamento experimental } & 27\end{array}$

4.3 Protocolo de exercício para induzir o dano muscular 29

4.4 Protocolos de recuperação 29

$\begin{array}{lll}4.5 & \text { Força muscular } & 30\end{array}$

4.6 Desempenho muscular (salto vertical) 30

4.7 Dor muscular de início tardio 31

$\begin{array}{lll}4.8 & \text { Creatina quinase } & 31\end{array}$

4.9 Temperatura da pele, conforto e sensação térmica 32

4.10 Análise estatística 32

5 RESULTADOS $\quad 34$

$\begin{array}{lll}5.1 & \text { Força muscular } & 34\end{array}$ 
5.3 Dor muscular de início tardio 36

$\begin{array}{lll}5.4 & \text { Creatina quinase } & 37\end{array}$

5.5 Temperatura da pele, conforto e sensação térmica 38

6 DISCUSSÃO 39

7 CONCLUSÃO $\quad 42$

8 REFERÊNCIAS 43

ANEXO A - Parecer do Comitê de Ética em Pesquisa em Seres Humanos 50 da UnB

ANEXO B - Aceite para publicação do manuscrito da tese 51

ANEXO C - Manuscrito aceito para publicação no periódico International 52 Journal of Sports Medicine 


\section{INTRODUÇÃO}

Dano muscular induzido pelo exercício (DMIE) é uma consequência comum do exercício não habitual, no qual músculos acometidos podem requerer vários dias para retornar ao seu estado funcional prévio (1). A regeneração tecidual após o DMIE depende de um processo orquestrado, envolvendo uma resposta inflamatória a qual inicia mecanismos de retroalimentação positiva resultando em uma infiltração de células inflamatórias no tecido danificado (2). Além disso, a magnitude da resposta inflamatória parece ser modulada pela extensão do dano tecidual (1,3). Enquanto a resposta inflamatória é fundamental para o reparo do tecido, uma resposta excessiva parece retardar o processo de regeneração $(2,3)$. Assim, estratégias terapêuticas que objetivam minimizar, ou de fato 'otimizar' a resposta inflamatória podem ser benéficas para 0 processo regenerativo e acelerar a recuperação muscular.

A crioterapia, o uso terapêutico do frio, é uma das modalidades mais utilizadas no tratamento agudo de lesões músculo esqueléticas (4). A racionalidade para o uso da crioterapia incluem: a) reduzir a taxa metabólica tecidual, permitindo que o tecido não lesionado adjacente ao dano sobreviva a um período de isquemia; e b) proteger o tecido sadio ao redor do dano contra as reações enzimáticas que podem acompanhar tanto o dano tecidual quanto as respostas inflamatórias $(4,5)$. A imersão em água gelada (IAG) atualmente é uma das formas mais utilizadas na recuperação pós-exercício (6). Parte desta popularidade deve se as suas propriedades anti-inflamatórias, bem como ao seu baixo custo e a facilidade de ser aplicada em uma grande área corporal $(3,7)$. Evidências sugerem que a IAG seja efetiva em reduzir a dor muscular $(6,8,9)$, porém seus efeitos sobre a recuperação da função muscular permanecem inconclusivos. Estudos propõe que a IAG possa acelerar a recuperação $(3,10-12)$, enquando outros não demonstraram nenhum benefício (13-15). Estes resultados conflitantes podem ser atribuidos as diferentes metodologias empregadas. De fato, não há um protocolo de IAG plenamente estabelecido e importantes parâmetros, tais como a temperatura da água, tem sido pouco controlados (8). Wilcock e colaboradores (7) sugerem que o efeito terapêutico da IAG pode ser percebido em temperaturas iguais ou inferiores a $15^{\circ} \mathrm{C}$, porém é comum 
estudos utilizando temperaturas entre $5 \stackrel{\circ}{C}$ (15) e $20 \stackrel{\circ}{C}$ (3). Recentemente, White e colaboradores (3) examinaram os efeitos de diferentes protocolos de IAG utilizando água resfriada a $10 \stackrel{\circ}{\circ}$ ou $20 \stackrel{\circ}{\circ}$, as quais foram aplicadas por 10 ou $30 \mathrm{~min}$. Os autores encontraram que todos os protocolos tiveram efeitos positivos na recuperação do desempenho do salto com contramovimento (SCM), exceto quando $20^{\circ} \mathrm{C}$ foi utilizado por $10 \mathrm{~min}$. Interessantemente, eles também observaram que os protocolos de IAG de excessiva duração podem aumentar, ao invés de reduzir, a resposta inflamatória (3). Estes resultados sugerem que uma maior atenção deveria ser dada sobre estes parâmetros e mais estudos comparando diferentes temperaturas da água ainda são necessários. A hipotése é que modalidades de crioterapia com maior capacidade de resfriamento (p.e. IAG a $5{ }^{\circ} \mathrm{C}$ ) poderiam produzir resultados superiores na recuperação muscular quando comparado a modalidades com menor capacidade de resfriamento (p.ex. IAG a $15^{\circ} \mathrm{C}$ ). 


\section{OBJETIVOS}

2.1 Investigar os efeitos de $5{ }^{\circ} \mathrm{C}$ e $15{ }^{\circ} \mathrm{C}$ de temperatura durante 20 minutos de IAG na recuperação da força isométrica após o DMIE.

2.2 Investigar os efeitos de $5 \stackrel{\circ}{\circ} \mathrm{C}$ e $15{ }^{\circ} \mathrm{C}$ de temperatura durante 20 minutos de IAG na recuperação do desempenho do SCM após o DMIE.

2.3 Investigar os efeitos de $5 \stackrel{\circ}{\circ} \mathrm{C}$ e $15{ }^{\circ} \mathrm{C}$ de temperatura durante 20 minutos de IAG na recuperação da percepção subjetiva de DMIT após o DMIE.

2.4 Investigar os efeitos de $5{ }^{\circ} \mathrm{C}$ e $15{ }^{\circ} \mathrm{C}$ de temperatura durante 20 minutos de IAG na recuperação dos níveis séricos da CK após o DMIE. 


\section{REVISÃO DE LITERATURA}

O uso do frio tem uma longa tradição como método de tratamento para uma grande variedade de desordens físicas. Registros apontam que há cerca de 4500 anos, os Egípcios foram os primeiros a utilizar as baixas temperaturas como um potencial meio de cura. Hipocrates e, posteriormente, Avicenna também fizeram uso do frio com propósitos terapêuticos $(16,17)$. Atualmente, a criomedicina é dividida em três vertentes, sendo: 1) crioproteção: associada a transplantologia e a farmacologia; 2) criodestruição: utilização dermatológica do frio para a destruição de tecidos indesejados, além de alguns procedimentos cirúrgicos; 3) crioterapia: o uso terapêutico do frio para o tratamento das mais diversas afecções osteomioarticulares (17). No entanto, seu uso pela medicina esportiva somente iniciou em meados da década de 50 , quando a crioterapia começou a ser utilizada no tratamento de lesões esportivas. A partir de 1970, o uso da crioterapia tornou-se um tratamento quase que universal para os cuidados imediatos de lesões esportivas (16). Desde então, a comunidade científica tem investigado a crioterapia no sentido de expandir a fundamentação teórica para o seu uso. Neste período o foco foi em conhecer os mecanismos de ação, além de claramente definir como e quando ela deveria ser utilizada.

Inicialmente a fundamentação para a utilização da crioterapia foi baseada em evidências que haviam demonstrado uma diminuição do fluxo sanguíneo, e por conseguinte menor formação de edema (18). Também foi proposto que o resfriamento do tecido acometido poderia aumentar a sobrevida das células adjacentes ao dano, devido a diminuição do metabolismo celular e das necessidades de oxigênio - conceito denominado de dano secundário a lesão (18). Posteriormente, estudos foram conduzidos a fim de determinar a magnitude ideal de resfriamento tecidual e quais seriam os melhores meios de resfriamento $(4,19)$. São várias as modalidades de crioterapia, sendo as mais comuns o pacote com gelo ou gel (aplicado com ou sem compressão), imersão em água gelada, massagem com gelo, sprays refrigerantes e ar refrigerado (16). Dentre estas, a imersão em água gelada vem sendo considerada uma das modalidades mais efetivas em sua ação terapêutica pela melhor eficiência no resfriamento durante a 
aplicação e na manutenção do resfriamento após sua remoção (20). Também é reconhecido que o tempo de aplicação deve ser em torno de 20 a $30 \mathrm{~min}$, sem efeito adicional quando a duração da aplicação é superior a esse período (16). Porém, algumas questões permanecem sem respostas, ainda não há um protocolo plenamente reconhecido de aplicação da crioterapia. Importantes parâmetros do protocolo de crioterapia, tais como a temperatura da água durante o protocolo de imersão em água gelada, bem como a quantidade de sessões requeridas para a recuperação tecidual ainda requerem estudos para serem elucidados.

\subsection{MECANISMOS ENVOLVIDOS NA CRIOTERAPIA}

Antes de mencionar os mecanismos pelos quais a crioterapia aceleraria a recuperação muscular, é necessário descrever o processo fisiológico que ocorre na célula muscular após a realização de um exercício físico intenso que leva a deterioração prolongada do desempenho físico. A hipótese da ruptura dos sarcômeros, proposta por Morgan em 1990 (24) fornece uma explicação para a diminuição prolongada da força muscular após o exercício, a qual vem sendo confirmada por outros estudos $(1,21,25$, 26). Durante as contrações excêntricas, as miofibrilas da fibra muscular são alongadas e aqueles sarcômeros mais fracos e de menor comprimento absorvem a maior parte da tensão gerada pelo alongamento. Após algumas contrações excêntricas, tais sarcômeros falham em se reconectar por terem sofrido uma ruptura. A repetição das ações excêntricas ocasiona a ruptura de mais sarcômeros, até o ponto em que ela levaria ao dano da membrana celular e do reticulo sarcoplasmático. Esse dano levaria a uma grande liberação de cálcio e em seguida a alteração do padrão excitação-contração. O processo de alteração morfológica da fibra muscular parece ser responsável pelos sintomas associados ao dano muscular induzido pelo exercício, tais como: redução prolongada da força muscular, dor muscular de início tardio, aumento da circulação de proteínas musculares na corrente sanguínea e início da resposta inflamatória $(1,21,25-28)$. 
Imediatamente após a ruptura dos sarcômeros, os leucócitos (neutrófilos, linfócitos e monócitos) são rapidamente mobilizados para o tecido danificado via moléculas de adesão do tipo 1. Em seguida, citocinas pró-inflamatórias e espécies reativas de oxigênios são produzidas na célula muscular pelos neutrófilos, linfócitos e monócitos (1, 21, 25, 26). Em adição, macrófagos produzidos por monócitos e neutrófilos fagocitam miofibras danificadas e detritos musculares. Juntos, leucócitos, citocinas próinflamatórias e espécies reativas de oxigênio causam degradação muscular, a qual amplifica o dano muscular primário $(1,21,25,26)$. Isto pode ser observado pelo aumento nas proteínas musculares na corrente sanguínea após o exercício. A magnitude do dano muscular secundário, o qual é gerado por tal processo inflamatório, dependerá do balanço entre a produção das citocinas pró e anti-inflamatórias (29).

Um modelo lógico considerando as razões fisiológicas para o uso da crioterapia tem sido proposto por Costello et al. (30) e Ferreira-Junior et al. (21). A crioterapia causa uma vasoconstrição associada com a diminuição da temperatura interna e muscular (31). Esta vasoconstrição causaria uma redução no aporte sanguíneo e consequentemente nas células imunes que irrigam o tecido com dano. A próxima etapa seria redução na migração de leucócitos (neutrófilos, linfócitos e monócitos) da circulação sanguínea para o tecido danificado (21). As respostas termorregulatórias à crioterapia aceleraria a recuperação muscular por reduzir os níveis de moléculas de adesão do tipo 1 (21). Consequentemente, poucos leucócitos migrariam para o interior da célula muscular, resultando na diminuição da resposta pró inflamatória (21). Esta redução na resposta inflamatória aguda proveria um papel benéfico por atenuar o dano muscular secundário e consequentemente diminuindo o edema, dor muscular e acelerando a recuperação da força muscular. O menor edema pode diminuir a pressão no local. Como consequência da diminuição da pressão, menor seria a ativação dos nociceptores, levando a redução da dor (25). Além disso, por meio da diminuição da temperatura da pele, a crioterapia pode diminuir a velocidade da condução do estímulo nervoso aferente e também a sensibilidade dos nociceptores, o que poderia contribuir para o alívio da dor (30). 


\subsection{CRIOTERAPIA DE IMERSÃO EM ÁGUA GELADA (IAG)}

A IAG é a modalidade de crioterapia mais utilizada, especialmente no meio esportivo (32). Este método consiste na combinação de gelo e água em um recipiente, no qual os sujeitos imergem o corpo todo ou apenas os membros (Figura 1) (7). Para que seja obtido os maiores benefícios da IAG é sugerido que seja realizada o mais breve possível após o término do exercício. Grande parte dos estudos que reportam resultado positivo realizaram o procedimento em até 30 minutos após o exercício. Adicionalmente, considerando os possíveis benefícios sistêmicos parece razoável que maior área possível seja submersa em água gelada, assim espera-se os maiores benefícios com a imersão do corpo inteiro quando comparado a imersões de apenas membros.

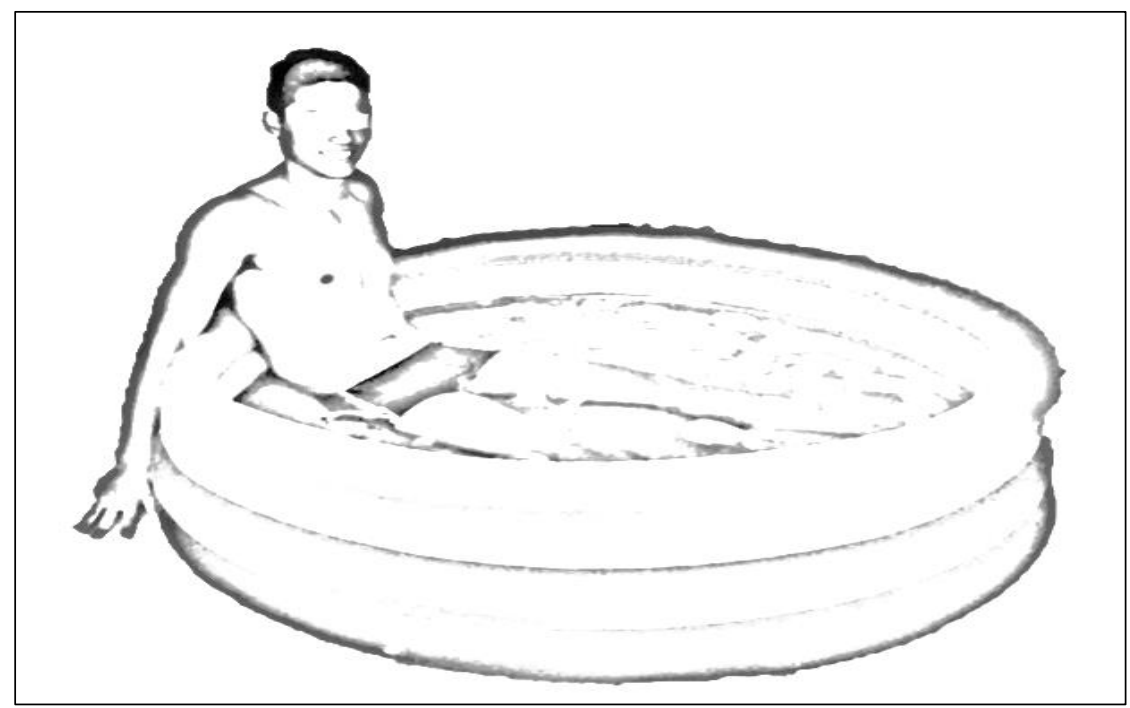

Figura 1 - Sessão de crioterapia de imersão em água gelada para membros inferiores.

Geralmente a duração da aplicação é de 10 a 20 minutos (7, 32), embora períodos de 30 segundos a cinco minutos também são frequentemente encontrados na literatura $(7,32)$. Evidências sugerem que os efeitos terapêuticos desta intervenção iniciam em temperaturas iguais ou inferiores a $15^{\circ} \mathrm{C}(7,33)$ chegando até $5^{\circ} \mathrm{C}(33)$. No entanto, 
poucas evidências têm fundamentado a determinação destas importantes variáveis, e até o momento, tem sido considerado meramente a tolerância ou a preferência dos sujeitos submetidos a intervenção (33). Além disso, a maior parte dos estudos envolve indivíduos jovens e saudáveis do sexo masculino. Dessa forma, outras populações podem requerer alguma alteração no protocolo. Por exemplo, indivíduos obesos podem necessitar de um maior tempo de exposição à IAG para que tenham um adequado resfriamento dos tecidos. Além disso, vale ressaltar que não há um protocolo plenamente estabelecido e alguns parâmetros são baseadas em fundamentações teóricas (34).

Aparentemente a IAG, bem como outras formas de crioterapia não oferecem riscos à saúde. De acordo com a literatura científica, sessões diárias $\mathrm{CWI}$, ou sessões únicas realizadas antes ou após o esforço físico não prejudicam o funcionamento dos sistemas cardiovascular ou imunológico (22). Todavia, sessões de crioterapia são contraindicadas para indivíduos que apresentem uma das seguintes condições $(35,36)$ : 1) hipertensão não tratada, 2) doença cardiovascular e respiratória severa, 3) doenças do trato urinário, 4) anemia severa, 5) alergia ao frio, 6) infecções virais e bacterianas, 7) síndrome de Reynaud, 8) claustrofobia e 9) convulsões.

\subsection{EFEITO AGUDO DA IMERSÃO EM ÁGUA GELADA NO DESEMPENHO NEUROMUSCULAR}

Durante a prática esportiva é comum atletas com pequenas lesões utilizarem a crioterapia e imediatamente após o tratamento retornarem à competição (37). O efeito agudo da IAG no desempenho muscular foi investigado por Schniepp e colaboradores (38). Eles examinaram o efeito de 15 min de imersão dos membros inferiores em água resfriada a $12^{\circ} \mathrm{C}$ sobre o sprint máximo de ciclistas. Imediatamente após houve uma redução de 13,7\% e 9,5\% nas potências máxima e média, respectivamente. A justificativa para esta redução do desempenho é fornecida por estudos que demonstraram menor velocidade de condução neural, por conseguinte menor atividade neuromuscular (EMG) e menor taxa de desenvolvimento de força (39). 
Por outro lado, efeito positivo da IAG foi encontrado quando o exercício subsequente foi realizado no calor $\left(35^{\circ} \mathrm{C}\right)$. Peiffer e colaboradores (40) aplicaram apenas 5 min de IAG com água resfriada a $14^{\circ} \mathrm{C}$. Neste estudo, 25 min de ciclismo em intensidade constante seguidos por $4 \mathrm{~km}$ de ciclismo contra-relógio foram realizados 5 min após a crioterapia. A possível explicação para o resultado positivo observado neste estudo foi a menor temperatura central observado ao longo de todo exercício subsequente.

Apesar das controversas acerca do efeito agudo da IAG sobre o desempenho motor tudo indica que o resfriamento do tecido exerce um efeito prejudicial no desempenho neuromuscular (37). Contudo, alguns atletas podem se beneficiar dos efeitos agudos do resfriamento, desde que haja tempo suficiente para o reaquecimento da musculatura e que a atividade não seja exclusivamente dependente da produção de potência muscular.

\subsection{EFEITO DA IMERSÃO EM ÁGUA GELADA NA RECUPERAÇÃO MUSCULAR}

Frequentemente entusiastas da prática esportiva e atletas de alto desempenho utilizam a IAG com o propósito de acelerar a recuperação do desempenho muscular. Recuperação muscular, é um termo amplo sendo habitualmente relacionado a restauração fisiológica e psicológica do organismo que permitirá o retorno do desempenho físico aos níveis iniciais antes do exercício (34). Dessa forma, o principal parâmetro que deve ser considerado é o desempenho propriamente dito, para o qual há inúmeras possibilidades de avaliação, exemplos são apresentados nos resultados da tabela 1. A seguir (tabela 1) estão listados estudos que avaliaram os efeitos da IAG que encontram algum efeito dessa modalidade sobre o desempenho muscular. No geral, a maior parte destes estudos apontam efeito positivo da IAG na recuperação muscular, porém há aqueles que não encontraram nenhum benefício ou mesmo outros que demonstraram efeito negativo. É importante ressaltar que não há um protocolo plenamente estabelecido e importantes variáveis são algumas vezes escolhidas de forma 
aleatória. Visualizando os protocolos de IAG descritos na tabela 1 podemos encontrar estudos que utilizaram água resfriada de $5^{\circ} \mathrm{C}$ a $20^{\circ} \mathrm{C}$, durações de aplicação de 1 min a 20 min. Essas aplicações foram feitas uma única vez imediatamente após o exercício, uma única vez após alguns minutos, ou por repetidas vezes após o exercício. Além disso, os estudos divergem quanto a população investigada, o protocolo de exercício, e o tipo de avaliação de desempenho. Essas questões aparentam contribuir para os resultados contraditórios observados.

Tabela 1. Estudos investigando o efeito da imersão em água gelada na recuperação do desempenho muscular. Foram reportados estudos que encontraram efeito positivo ou negativo no desempenho muscular. Estudos que não encontram nenhum efeito significativo foram omitidos.

\begin{tabular}{|c|c|c|c|c|}
\hline Estudo & Participantes & $\begin{array}{l}\text { Protocolo de } \\
\text { Exercícios }\end{array}$ & Protocolo de IAG & Resultado \\
\hline $\begin{array}{l}\text { Ascensão et } \\
\text { al. } 2011 \text { (41) }\end{array}$ & $\begin{array}{l}\text { Jogadores de } \\
\text { futebol } \\
\text { (categoria jr) }\end{array}$ & Partida amistosa & $\begin{array}{l}0 \text { min após exercício, } 10^{\circ} \mathrm{C} \\
\text { por } 10 \text { min, imersão de } \\
\text { MMII }\end{array}$ & $\uparrow \mathrm{CVM} 24 \mathrm{~h}$ \\
\hline $\begin{array}{l}\text { Bailey et al. } \\
2007 \text { (42) }\end{array}$ & $\begin{array}{l}\text { Adultos } \\
\text { ativos }\end{array}$ & $\begin{array}{l}90 \text { min de shuttle run } \\
\text { (corrida intermitente) }\end{array}$ & $\begin{array}{l}0 \text { min após exercício, } 10^{\circ} \mathrm{C} \\
\text { por } 10 \mathrm{~min} \text {, imersão de } \\
\text { MMII }\end{array}$ & $\begin{array}{l}\uparrow \text { CVM 24h e } \\
48 \mathrm{~h}\end{array}$ \\
\hline $\begin{array}{l}\text { Brophy- } \\
\text { Williams et al. } \\
2011 \text { (43) }\end{array}$ & $\begin{array}{l}\text { Atletas de } \\
\text { esportes } \\
\text { coletivos }\end{array}$ & $\begin{array}{l}\text { HIT }(8 \times 3 \text { min a } 90 \% \\
\text { VVO2max) }\end{array}$ & $\begin{array}{l}0 \text { min e } 3 \text { h após exercício, } \\
15^{\circ} \mathrm{C} \text { por } 15 \mathrm{~min} \text {, imersão } \\
\text { do corpo todo }\end{array}$ & $\begin{array}{l}\uparrow \text { desempenho } \\
\text { do yoyo teste } \\
\text { quando a IAG } \\
\text { foi realizada } 0 \\
\text { min após o } \\
\text { exercicio }\end{array}$ \\
\hline $\begin{array}{l}\text { Crowe et al. } \\
2007(44)\end{array}$ & $\begin{array}{l}\text { Treinados } \\
\text { em força ou } \\
\text { atletas de } \\
\text { esportes } \\
\text { coletivos }\end{array}$ & $\begin{array}{l}\text { Teste de Wingate } \\
\text { (ciclo) }\end{array}$ & $\begin{array}{l}0 \text { min após exercício, } 13- \\
14^{\circ} \mathrm{C} \text { por } 15 \mathrm{~min} \text {, imersão } \\
\text { de } \mathrm{MMII}\end{array}$ & $\begin{array}{l}\downarrow \text { potência pico } \\
\text { e trabalho }\end{array}$ \\
\hline $\begin{array}{l}\text { Heyman et al. } \\
2009(45)\end{array}$ & Escaladores & $\begin{array}{l}\text { Escalada indoor por } \\
\text { rota pré-determinada }\end{array}$ & $\begin{array}{l}0 \text { min após exercício, } 15^{\circ} \mathrm{C} \\
\text { sendo } 3 \times 5 \text { com } 2 \text { min } \\
\text { intervalo, imersão de } \\
\text { MMSS }\end{array}$ & $\begin{array}{l}\uparrow \text { desempenho } \\
\text { na escalada }\end{array}$ \\
\hline $\begin{array}{l}\text { Higgins et al. } \\
2011 \text { (46) }\end{array}$ & $\begin{array}{l}\text { Atletas de } \\
\text { rúgbi }\end{array}$ & $\begin{array}{l}\text { Jogo de rugbi }+2 \\
\text { sessões de } \\
\text { treino/semana, } \\
\text { durante } 4 \text { semanas }\end{array}$ & $\begin{array}{l}0 \text { min após exercício, } 10- \\
12^{\circ} \mathrm{C} \text { por } 5 \text { min, imersão de } \\
\text { MMII }\end{array}$ & $\begin{array}{l}\downarrow \text { desempenho } \\
\text { nos sprints } \\
\text { repetidos }\end{array}$ \\
\hline $\begin{array}{l}\text { Ingram et al. } \\
2009(47)\end{array}$ & $\begin{array}{l}\text { Experientes } \\
\text { em esportes } \\
\text { coletivos }\end{array}$ & $\begin{array}{l}\text { Jogo simulado ( } 4 \times 20 \\
\text { min corrida } \\
\text { intermitente), teste }\end{array}$ & $\begin{array}{l}0 \text { min e } 24 \mathrm{~h} \text { após o } \\
\text { exercício, } 10^{\circ} \mathrm{C} \text { sendo } 2 \times 5 \\
\text { min com } 2,5 \text { min de } \\
\text { intervalo, imersão de MMII }\end{array}$ & $\begin{array}{l}\uparrow \text { flexão e } \\
\text { extensão do } \\
\text { joelho; } \uparrow\end{array}$ \\
\hline
\end{tabular}




\begin{tabular}{|c|c|c|c|c|}
\hline & & $\begin{array}{l}\text { de shuttle-run de } \\
20 \mathrm{~m}\end{array}$ & & $\begin{array}{l}\text { desempenho } \\
\text { sprints }\end{array}$ \\
\hline $\begin{array}{l}\text { King \& Duffield } \\
2009 \text { (12) }\end{array}$ & $\begin{array}{l}\text { Atletas de } \\
\text { netball }\end{array}$ & $\begin{array}{l}\text { Circuito simulado de } \\
\text { netball, envolvendo } \\
\text { sprints repetidos }\end{array}$ & $\begin{array}{l}0 \text { min e } 24 \mathrm{~h} \text { após o } \\
\text { exercício, } 9^{\circ} \mathrm{C} \text { sendo } 2 \times 5 \\
\text { com } 2,5 \text { de intervalo, } \\
\text { imersão de MMII }\end{array}$ & $\uparrow$ salto vertical \\
\hline $\begin{array}{l}\text { Lane \& } \\
\text { Wenger } 2004 \\
(48)\end{array}$ & $\begin{array}{l}\text { Fisicamente } \\
\text { ativos }\end{array}$ & $\begin{array}{l}18 \text { min de ciclismo } \\
(\mathrm{HIT})\end{array}$ & $\begin{array}{l}0 \text { min após o exercício, } \\
15^{\circ} \mathrm{C} \text { por } 15 \mathrm{~min} \text {, imersão } \\
\text { de } \mathrm{MMII}\end{array}$ & $\uparrow$ Trabalho total \\
\hline $\begin{array}{l}\text { Montegomery } \\
\text { et al. } 2008 \\
\text { (49) }\end{array}$ & $\begin{array}{l}\text { Jogadores } \\
\text { de basquete }\end{array}$ & $\begin{array}{l}\text { Torneio de basquete } \\
\text { (1 jogo por dia, } \\
\text { durante } 3 \text { dias; } 48 \\
\text { min cada jogo) }\end{array}$ & $\begin{array}{l}0 \text { min após o exercício, } \\
11^{\circ} \mathrm{C} \text { sendo } 5 \times 1 \text { com } 2 \text { min } \\
\text { intervalo, imersão do corpo } \\
\text { todo }\end{array}$ & $\begin{array}{l}\uparrow \text { desempenho } \\
\text { no sprint de } \\
20 \mathrm{~m}, \uparrow \text { salto } \\
\text { vertical, } \uparrow \text { teste } \\
\text { de habilidade }\end{array}$ \\
\hline $\begin{array}{l}\text { Parouty et al. } \\
2010(50)\end{array}$ & Nadadores & $\begin{array}{l}\text { 100-m livre de } \\
\text { natação }\end{array}$ & $\begin{array}{l}5 \text { min após exercício, } 14- \\
15^{\circ} \mathrm{C} \text { por } 5 \text { min, imersão do } \\
\text { corpo todo }\end{array}$ & $\begin{array}{l}\downarrow \text { desempenho } \\
\text { nado }\end{array}$ \\
\hline $\begin{array}{l}\text { Peiffer et al. } \\
2009(51)\end{array}$ & Ciclistas & $\begin{array}{l}90 \text { min de ciclismo a } \\
80 \% \text { do } 2^{\circ} \text { limiar } \\
\text { ventilatório }+16,1 \mathrm{~km} \\
\text { contra-relógio }\end{array}$ & $\begin{array}{l}25 \text { min após exercício, } \\
14^{\circ} \mathrm{C} \text { por } 20 \mathrm{~min} \text {, imersão } \\
\text { do corpo todo }\end{array}$ & $\downarrow \mathrm{CVM}$ \\
\hline $\begin{array}{l}\text { Peiffer et al. } \\
2010(40)\end{array}$ & Ciclistas & $\begin{array}{l}25 \text { min ciclismo a } \\
65 \% \text { VO2max }+4 \mathrm{~km} \\
\text { contra-relógio }\end{array}$ & $\begin{array}{l}5 \text { min após o exercício, } \\
14^{\circ} \mathrm{C} \text { por } 5 \text { min, imersão do } \\
\text { corpo todo }\end{array}$ & $\begin{array}{l}\uparrow \text { potência } \\
\text { média e do } \\
\text { desempenho } \\
\text { nos } 4 \mathrm{~km}\end{array}$ \\
\hline $\begin{array}{l}\text { Pournot et al. } \\
2011(52)\end{array}$ & $\begin{array}{l}\text { Atletas } \\
\text { futebol, } \\
\text { rugby e volei }\end{array}$ & $\begin{array}{l}\text { Exercício } \\
\text { intermitente (saltos e } \\
\text { remo ergômetro) } \\
\text { ( } 2 \times 10 \text { min, } 10 \text { min } \\
\text { intervalo }\end{array}$ & $\begin{array}{l}0 \text { min após o exercício, } \\
10^{\circ} \mathrm{C} \text { por } 15 \text { min, imersão } \\
\text { de MMII }\end{array}$ & $\uparrow \mathrm{CVM} 1 \mathrm{~h}$ \\
\hline $\begin{array}{l}\text { Rowsell et al. } \\
2011 \text { (53) }\end{array}$ & $\begin{array}{l}\text { Jogadores } \\
\text { de futebol } \\
\text { sub-17 }\end{array}$ & $\begin{array}{l}4 \text { dias de torneio de } \\
\text { futebol, } 1 \text { jogo por } \\
\text { dia }\end{array}$ & $\begin{array}{l}10 \text { min após o exercício, } \\
10^{\circ} \mathrm{C} \text { sendo } 5 \times 1 \text { min com } 1 \\
\text { min de intervalo, imersão } \\
\text { do corpo todo }\end{array}$ & $\begin{array}{l}\uparrow \text { distância } \\
\text { percorrida }\end{array}$ \\
\hline $\begin{array}{l}\text { Schniepp et al. } \\
2002(38)\end{array}$ & Ciclistas & $\begin{array}{l}\text { 360-m de ciclismo } \\
\text { (sprint) }\end{array}$ & $\begin{array}{l}0 \text { min após o exercício, } \\
12^{\circ} \mathrm{C} \text { por } 15 \text { min, imersão } \\
\text { de MMII }\end{array}$ & $\begin{array}{l}\downarrow \text { potência } \\
\text { média e } \\
\text { máxima }\end{array}$ \\
\hline $\begin{array}{l}\text { Skurvydas et } \\
\text { al. } 2006 \text { (10) }\end{array}$ & $\begin{array}{l}\text { Homens } \\
\text { fisicamente } \\
\text { ativos }\end{array}$ & $\begin{array}{l}100 \text { saltos em } \\
\text { profundiade }(75 \mathrm{~cm})\end{array}$ & $\begin{array}{l}0,4,8 \text { e } 24 \text { h pós-exercício, } \\
15^{\circ} \mathrm{C} \text { em } 2 \times 15 \text { min }\end{array}$ & $\begin{array}{l}\uparrow \text { desempenho } \\
\text { salto e a CVM }\end{array}$ \\
\hline $\begin{array}{l}\text { Vaile et al. } \\
2008 \text { (11) }\end{array}$ & Ciclistas & $\begin{array}{l}15 \text { min de ciclismo a } \\
75 \% \text { potência }\end{array}$ & $\begin{array}{l}0 \text { min após o exercício, } \\
\text { comparação de diferentes } \\
\text { protocolos usando } 10^{\circ} \mathrm{C}, \\
15^{\circ} \mathrm{C} \text { e } 20^{\circ} \mathrm{C} \text { em } 5 \times 1 \mathrm{com} 2\end{array}$ & $\begin{array}{l}\uparrow \text { desempenho } \\
\text { no contra- } \\
\text { relógio }\end{array}$ \\
\hline
\end{tabular}




\begin{tabular}{|c|c|c|c|c|}
\hline & & $\begin{array}{l}\text { aeróbia }+15 \min \\
\text { contra-relógio }\end{array}$ & $\begin{array}{l}\text { min de intervalo, e } 20^{\circ} \mathrm{C} \\
\text { por } 15 \text { min; imersão do } \\
\text { corpo todo }\end{array}$ & \\
\hline $\begin{array}{l}\text { Vaile et al. } \\
2008 \text { (54) }\end{array}$ & Ciclistas & $\begin{array}{l}\text { Ciclismo de alta } \\
\text { intensidade (sprints) }\end{array}$ & $\begin{array}{l}0 \text { min após o exercício } \\
\text { (uma vez ao dia; durante } 4 \\
\text { dias), } 15^{\circ} \mathrm{C} \text { por } 14 \text { min, } \\
\text { imersão do corpo todo }\end{array}$ & $\begin{array}{l}\uparrow \text { desempenho } \\
\text { no Sprint }\end{array}$ \\
\hline $\begin{array}{l}\text { Vaile et al. } \\
2008(55)\end{array}$ & $\begin{array}{l}\text { Treinados } \\
\text { em força }\end{array}$ & $\begin{array}{l}\text { Leg press excêntrico } \\
(5 \times 10 \text { reps a } 120 \% \\
1-\mathrm{RM} \text { concêntrica + } \\
2 \times 10 \text { a } 100 \%)\end{array}$ & $\begin{array}{l}0 \text { min após o exercício } \\
\text { (uma vez ao dia; durante } 4 \\
\text { dias), } 15^{\circ} \mathrm{C} \text { por } 14 \text { min, } \\
\text { imersão do corpo todo }\end{array}$ & $\begin{array}{l}\uparrow \mathrm{CVM} \\
\text { agachamento e } \\
\text { potência no } \\
\text { agachamento } \\
\text { com salto }\end{array}$ \\
\hline $\begin{array}{l}\text { Vaile et al. } \\
2011(56)\end{array}$ & Ciclistas & $\begin{array}{l}15 \text { min de ciclismo a } \\
75 \% \text { potência } \\
\text { aeróbia }+15 \text { min } \\
\text { contra-relógio }\end{array}$ & $\begin{array}{l}0 \text { min após o exercício, } \\
15^{\circ} \mathrm{C} \text { por } 15 \mathrm{~min} \text {, imersão } \\
\text { corpo todo, até o ombro }\end{array}$ & $\begin{array}{l}\uparrow \text { desempenho } \\
\text { no contra- } \\
\text { relógio }\end{array}$ \\
\hline $\begin{array}{l}\text { White et al. } \\
2014 \text { (3) }\end{array}$ & $\begin{array}{l}\text { Homens } \\
\text { fisicamente } \\
\text { ativos }\end{array}$ & $\begin{array}{l}12 \text { sprints máximos } \\
\text { de } 120 \mathrm{~m}\end{array}$ & $\begin{array}{l}15 \text { min após o exercício. } \\
\text { Diferentes protocolos de } \\
10^{\circ} \mathrm{C} \text { e } 20^{\circ} \mathrm{C} \text { com } 10 \text { ou } 20 \\
\min \end{array}$ & $\begin{array}{l}\uparrow \text { desempenho } \\
\text { SCM }\end{array}$ \\
\hline $\begin{array}{l}\text { Yeargin et al. } \\
2006(57)\end{array}$ & Corredores & $\begin{array}{l}90 \text { min de corrida } \\
\text { com intensidade } \\
\text { moderada em } \\
\text { terreno acidentado }\end{array}$ & $\begin{array}{l}2-4 \text { min após o exercício, } \\
5^{\circ} \mathrm{C} \text { e/ou } 14^{\circ} \mathrm{C} \text { por } 12 \mathrm{~min}, \\
\text { imersão do corpo todo } \\
\text { (excluindo pés) }\end{array}$ & $\begin{array}{l}\uparrow \text { desempenho } \\
\text { na corrida com } \\
\text { imersão a } \\
14^{\circ} \mathrm{C} \text {. }\end{array}$ \\
\hline
\end{tabular}

\subsection{EFEITO DA IMERSÃO EM ÁGUA GELADA NA DOR MUSCULAR DE INÍCIO} TARDIO

A dor muscular de início tardio (DMIT) é frequentemente reportada como um fator de grande importância para a recuperação do desempenho, uma vez que a DMIT pode negativamente afetar o desempenho muscular. Neste contexto a IAG emerge como uma das intervenções mais populares em prevenir ou minimizar os impactos da DMIT sobre o desempenho, e por conseguinte permitindo melhor recuperação após o exercício. Essa popularidade também é fundamentada por revisões sistemáticas que encontraram resultados superiores da crioterapia em relação a diversas outras estratégias de 
recuperação $(6,8,9)$. Os mecanismos propostos para sua ação, seriam: 1$)$ propriedades anti-inflamatórias, 2) menor formação de edema; 3) diminuição na velocidade de condução nervosa; e 4) aumento no limiar de disparo dos receptores sensoriais. No entanto, o possível benefício da IAG no alívio da DMIT foram recentemente contestados, quando foram meramente atribuídos ao efeito placebo da intervenção (58). Neste sentido, Bleakley e colaboradores (6) realizaram uma revisão robusta da literatura sobre o efeito da IAG na DMIT analisando 17 estudos, que envolveram 366 participantes. Estes pesquisadores observaram que a crioterapia apresentou efeito positivo na maioria dos estudos nas $96 \mathrm{~h}$ seguintes ao exercício, especialmente quando o protocolo de exercício envolveu a corrida. No entanto, a pequena magnitude do efeito $(0,55$ a $0,95 \mathrm{em}$ uma escala de 0 a 10) é por muitos considerada clinicamente irrelevante.

\subsection{EFEITO DA IMERSÃO EM ÁGUA GELADA NA CONCENTRAÇÃO SANGUÍNEA DE CREATINA QUINASE}

Diversas proteinas intramusculares são liberadas na corrente sanguínea em decorrência do DMIE, e consequentemente podem ser utilizadas como marcadores de dano. Dentre estas proteinas a creatina quinase $(C K)$ tem recebido a maior parte da atenção devido a grande magnitude de seu aparecimento em resposta ao exercício de alta intensidade $(25,59)$. O aparecimento da CK na corrente sanguínea é decorrente de uma perda da integralidade da membrana da fibra muscular, permitindo então que a esta molécula seja liberada pelo tecido muscular. A CK é em grande parte liberada no sistema linfático, onde é transportada até o ducto torácico e finalmente liberada na corrente sanguínea. Esta cinética atrasa parte do aparecimento desta molécula na corrente sanguínea, o que foi demonstrado por estudos que observaram seu pico sanguíneo de cinco a sete dias após o insulto inicial $(60,61)$.

Talvez um dos maiores problemas na utilização deste marcador é a enorme variabilidade intra-sujeitos, sendo relativamente comum encontrar valores de 250 a $25.000 \mathrm{IU} / \mathrm{L}$ em resposta ao exercício (60). Essa variabilidade na resposta pode estar relacionada à outros fatores além do exercício, tais como o aumento da atividade da 
glutationa sérica (62). Gunst e colaboradores (62) observaram relação entre os níveis endógenos da glutationa com os níveis séricos da CK, sugerindo que a glutationa pode aumentar a meia-vida da CK na corrente sanguínea.

Independente das limitações na utilização da CK como marcardor de dano muscular, tem sido encontrado relação entre o trabalho realizado pelo músculo, magnitude do DMIE, e subsequente aparecimento da CK no sangue $(60,63)$. Dessa forma, a CK tem sido o biomarcador sanguíneo mais utilizado nos estudos que investigaram DMIE, assim estudos que investigam o efeito da crioterapia na recuperação muscular também consideram esta molécula como um importante marcador de dano. Todavia, são controversos os resultados a cerca do efeito da crioterapia na concentração de CK após DMIE. Há estudos $(10,55)$ que demonstraram que a crioterapia reduziu as concentrações de CK após o DMIE, porém outros $(14,15)$ não encontraram diferença alguma. Recentemente uma revisão sistemática com metanálise reportou que a IAG parece ser ineficaz em remover/diminuir as concentrações sanguíneas de CK durante a recuperação do DMIE. Portanto, futuros estudos ainda são necessários para investigar se diferentes protocolos de crioterapia seriam capazes de influenciar o aparecimento da CK na corrente sanguínea após o DMIE. 


\section{MÉTODOS}

\subsection{PARTICIPANTES}

O cálculo amostral foi realizado 'a priori utilizando o software G*Power (versão 3.1.2). Foram considerados as seguintes espeficações: erro tipo I $(\alpha)=0,05$; erro tipo II $(1-\beta)=0,8$; tamanho do efeito $(f)=0,2$; e teste estatístico $=$ análise de variância (ANOVA) de medidas repetidas com interação intra- e inter-grupos. O tamanho do efeito $(f)$ de 0,2 foi usado para detectar 'pequenas' diferenças, a qual foi baseada em um estudo recente que utilizou um protocolo experimental similar ( $f=0,26$; ref 35 ). A amostra foi estimada em 42 participantes. Dessa forma, quarenta e dois homens universitários foram recrutados para participar deste estudo. Os dados demográficos de cada um dos grupos de participantes é apresentado na Tabela 2. Foram selecionados apenas indivíduos fisicamente ativos que estivessem participando de atividades de leve a moderada intensidades (p.ex., caminhada, corridas, atividades recreativas) de 2 a 3 vezes na semana. Para aumentar a probabilidade de DMIE, indivíduos que participavam de atividades envolvendo exercício pliométricos e/ou treinamento resistidos foram excluídos do estudo. Também foram excluídos quando a dobra cutânea da coxa foi superior a 20 $\mathrm{mm}$ ou o torque dos extensores do joelho foi inferior a $185 \mathrm{~N} . \mathrm{m}$. Os participantes foram considerados aptos a realizarem o protocolo de exercício utilizado neste estudo após responderem "não" para todas as questões do Questionário de Prontidão para Atividades Físicas (PAR-Q). Os participantes não faziam uso de medicamentos e estavam livres de qualquer desordem cardiorrespiratória, muscular esquelética ou possíveis reações adversas ao frio, tais como Sindrome de Raynauld. Os participantes foram informados dos propósitos, procedimentos, desconfortos, riscos e benefícios antes de partiparem do estudo. Participaram aqueles que concordaram e assinaram o termo de concentimento livre e esclarecido. Este estudo foi aprovado pelo comite de ética institucional da Universidade de Brasília (Aprovação número 243/13). 
Tabela 2. Características físicas basais dos participantes do estudo

\begin{tabular}{lcccc}
\hline Características & G5 & G15 & GC & ${ }^{a} \boldsymbol{p}$ \\
\hline Idade (anos) & $22,1 \pm 2,5$ & $20,2 \pm 2,5$ & $20,2 \pm 1,7$ & 0,06 \\
Massa corporal (kg) & $74,4 \pm 12,9$ & $70,0 \pm 7,4$ & $71,3 \pm 9,4$ & 0,49 \\
Estatura (cm) & $175,2 \pm 5,2$ & $175,9 \pm 7,2$ & $175,7 \pm 7,2$ & 0,96 \\
Gordura corporal (\%) & $12,4 \pm 5,0$ & $10,2 \pm 5,2$ & $12,7 \pm 6,8$ & 0,44 \\
Dobra cutânea da coxa (mm) & $13,4 \pm 4,1$ & $12,1 \pm 4,2$ & $13,6 \pm 6,2$ & 0,66 \\
Torque (N.m) & $271,7 \pm 34,6$ & $245,8 \pm 36,6$ & $250,2 \pm 43,5$ & 0,18 \\
SCM (cm) & $44,5 \pm 4,5$ & $43,5 \pm 6,3$ & $46,6 \pm 5,1$ & 0,44 \\
\hline
\end{tabular}

ane-way ANOVA. G5 = grupo tratado com imersão em água gelada (IAG) a $5{ }^{\circ} \mathrm{C}, \mathrm{G} 15$ = grupo tratado com IAG a $15^{\circ} \mathrm{C}, \mathrm{GC}=$ grupo controle, Torque = torque dos extensores do joelho, SCM $=$ salto com contramovimento

\subsection{DELINEAMENTO EXPERIMENTAL}

A figura 2 sumariza o delineamento experimental deste estudo. Devido a possível influência do efeito da carga repetida na magnitude do dano muscular, bem como em sua recuperação (64), um delineamento com grupos independentes foi escolhido para este estudo. Dessa forma, os 42 participantes foram alocados em um dos três grupos experimentais, sendo: 1) IAG a $5 \stackrel{\circ}{\circ}(\mathrm{G} 5, \mathrm{n}=14)$; 2$)$ IAG a $15 \stackrel{\circ}{\circ} \mathrm{C}(\mathrm{G} 15, \mathrm{n}=14)$; ou 3$)$ controle ( $G C, n=14)$. Os participantes visitaram o laboratório em sete ocasiões. $\mathrm{Na}$ primeira visita foram realizados os procedimentos para a familiarização com os testes realizados no estudo (e.x. medida de torque isométrico, técnicas utilizadas nos saltos verticais), bem como foram realizadas as medidas antropométricas. De três a sete dias após a familiarização, os indivíduos realizaram cinco séries de 20 repetições para induzir o dano muscular (65). Quatro variáveis foram escolhidos como marcadores indiretos de DMIE: 1) força muscular; 2) desempenho no salto com contramovimento (SCM); 3) dor muscular de início tardio (DMIT); e 4) atividade sérica da creatina quinase (CK). Estas variáveis foram incluídas pois tem sido frequentemente utilizadas em estudos que investigaram a presença de DMIE (8). As variáveis foram medidas antes (Pré), 
imediatamente após (Pós), e 24, 48, 72, 96 e 168 horas pós-exercício. DMIT não foi medida Pós, e a CK não foi medida nos momento Pós e 96h pós-exercício. Os indivíduos alocados nos grupos de IAG foram submetidos a uma única imersão com 20 min de duração, a qual foi realizada imediatamente após as medidas dos marcadores de dano pós-exercício, enquanto que aqueles alocados no GC permaneceram sentados pelo mesmo período. Os participantes foram solicitados a retornar ao laboratório na mesma hora do dia $( \pm 1 \mathrm{~h})$ para os testes subsequentes. Não foi permitido nenhum tipo de atividade física vigorosa ou exercício não habitual, bem como o uso de medicações e o consumo de suplementos alimentares durante o período do experimento.

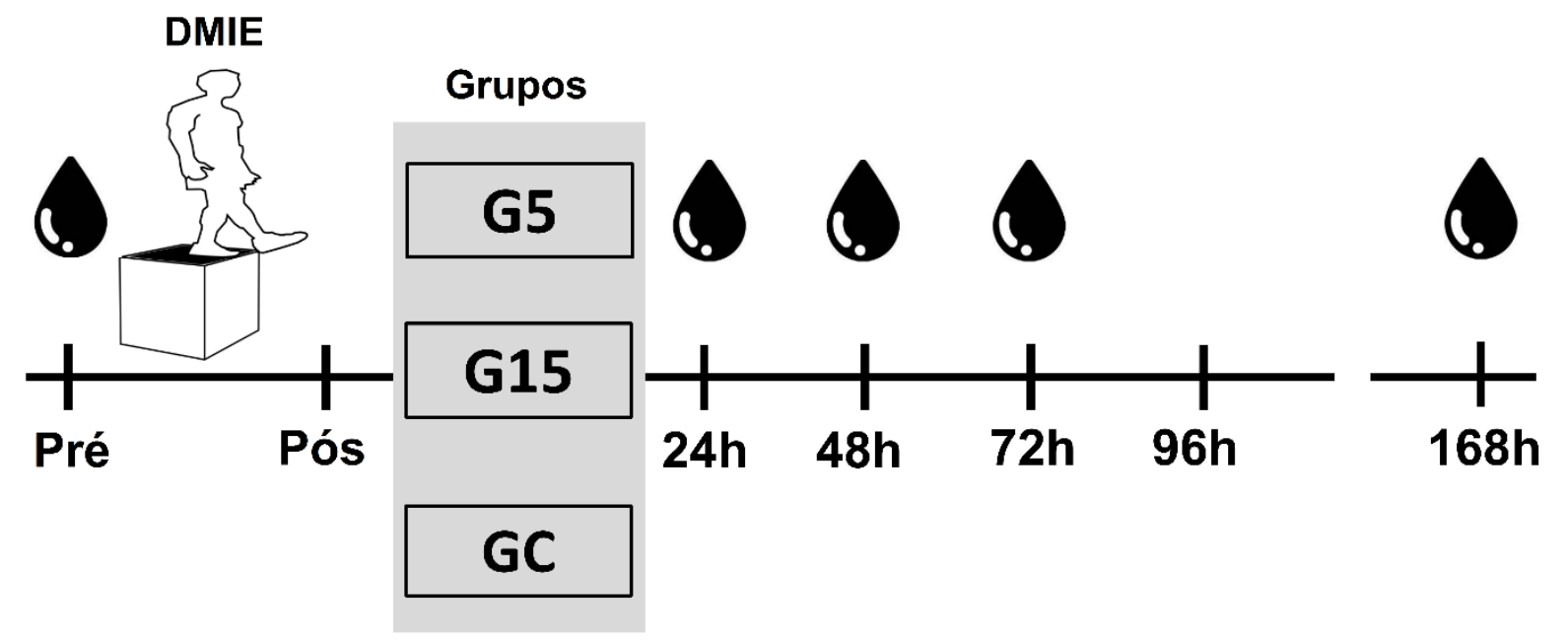

Figura 2. Delineamento experimental. As linhas verticais indicam o momento quando os marcadores indiretos de dano muscular indizido pelo exercício (DMIE) foram mensurados, sendo torque dos extensores do joelho, salto contramovimento, dor muscular de início tardio e creatina quinase. Dor muscular de início tardio não foi mensurada no momento 'Pós'. As gotas representam quando as amostras sanguíneas foram coletadas para medir a concentração sérica de creatina quinase. G5: imersão em água gelada (IAG) a 5 우 ; G15: IAG a $15{ }^{\circ} \mathrm{C}$; GC: grupo controle. 


\subsection{PROTOCOLO DE EXERCÍCIO PARA INDUZIR O DANO MUSCULAR}

O protocolo consistiu na realização de cinco séries de 20 repetições de salto em profundidade a partir de uma caixa com $60 \mathrm{~cm}$ de altura. Houve um intervalo de $2 \mathrm{~min}$ para recuperação entre as séries. Após a aterrisagem, os indivíduos foram instruídos a realizar um salto vertical de maneira explosiva. Eles também foram instruídos a fletir os joelhos a pelo menos $90^{\circ}\left(0^{\circ}=\right.$ extensão completa) durante todas as aterrisagens, enquanto mantinham as mãos no quadril. Eles foram encorajados a realizar o máximo esforço durante cada salto (mais alto possível). Este protocolo foi escolhido pois envolve grande massa muscular de múltiplas articulações, bem como utiliza o ciclo alongamentoencurtamento (CAE) e produz resposta similar a qual poderia ser obtida durante exercício de alta intensidade. Protocolo similar a este tem sido utilizado com frequência em diversos outros estudos objetivando o $\operatorname{DMIE}(13,14,65,66)$.

\subsection{PROTOCOLOS DE RECUPERAÇÃO}

Neste estudo os protocolos de IAG foram aplicados uma única vez após as medidas de força e desempenho muscular. A duração da aplicação da IAG foi de 20 min. Os indivíduos permaneceram sentados enquanto submergiram seus membros inferiores até que as cristas ilíacas estivessem submersas. A água foi mantida nas temperaturas de $5 \pm 1$ ou $15 \pm 1{ }^{\circ} \mathrm{C}$ através da adição de gelo triturado sempre que necessário. Os indivíduos foram instruídos a realizar movimentos circulares com as pernas a cada dois minutos para previnir a formação de uma camada de água mais quente ao redor da pele. O grupo controle permaneceu quietamente sentado em uma sala com temperatura ambiente pela mesma duração. Após completar as suas respectivas intervenções os participantes foram liberados para continuar as suas atividade de regulares. 


\subsection{FORÇA MUSCULAR}

O torque isométrico dos extensors do joelho foi mensurado no ângulo de $60^{\circ}\left(0^{\circ}=\right.$ extensão completa) em um dinamômetro (Biodex System 3, Biodex Medical, Inc., Shirley, New York, USA). Indivíduos foram confortavelmente posicionados na cadeira do dinamômetro com cintos cruzados sobre o tronco e ao redor da pelve para minimizar movimentos corporais que poderiam afetar o torque. O epicôndilo lateral do femur foi alinhado com o eixo do dinamômetro e os ajustes foram registrados para cada participante na sessão de familiarização para que fossem usados nos testes subsequentes. Durante o teste, os voluntários permaneceram com os braços cruzados no tórax e contraíram isometricamente os músculos extensores do joelho por 4 segundos. Indivíduos tiveram duas tentativas para alcançar o torque máximo e eles tiveram um minuto de intervalo entre as tentativas. Os participantes receberam encorajamento verbal para realizar o máximo esforço e todos os testes foram conduzidos pelo mesmo examinador.

\subsection{DESEMPENHO MUSCULAR (SALTO VERTICAL)}

A altura do SCM foi mensurada em uma plataforma de força (model BP400600HF-2000; Advanced Mechanical Technology, Inc., Watertown, MA, USA) com uma frequência amostral de $1000 \mathrm{~Hz}$. Este teste requer a utilização do CAE e tem sido considerado uma das medidas mais representativa da função muscular $(67,68)$. Os voluntários foram solicitados a manter as mãos no quadril e saltar o mais alto possível. Eles tiveram três tentativas para obter o melhor desempenho com um minuto de intervalo entre cada tentativa. Os participantes escolheram a amplitude de movimento que produzisse o salto mais alto e receberam encorajamento verbal pelo mesmo avaliador. Os dados obtidos durante os saltos foram capturados através do software do fabricante da plataforma (AMTI Acquisition Software, v 4.2; Advanced Mechanical Technology, Inc.) 
e foram posteriormente processados através de uma rotina elaborada em MATLAB ( $v$ R2008a7, The MathWorks Inc., Natick, MA, USA). A partir dos dados da força de reação contra o solo, a curva de deslocamento foi calculada, e então integrada para obter 0 deslocamento do centro de massa a cada instante do movimento. O maior deslocamento vertical foi considerado a altura máxima do salto, a qual foi utilizada nas análises posteriores.

\subsection{DOR MUSCULAR DE INÍCIO TARDIO}

A percepção subjetiva de dor nos músculos do quadríceps foi avaliada usando uma escala visual de $10 \mathrm{~cm}$. A escala inicia em "nenhuma dor", indo até "dor severa". Os participantes relataram a dor no quadriceps em duas condições: 1) contração isométrica voluntária máxima; e 2) sentar-e-levantar: três movimentos consecutivos de sentar e levantar de uma cadeira com $43 \mathrm{~cm}$ de altura, os quais foram realizados na cadência de dois segundos para sentar e dois seguntos para levantar (15).

\subsection{CREATINA QUINASE}

O sangue foi coletado a partir da veia cubital através da técnica padrão de venopunção utilizando um kit comercial Vacutainer. O sangue foi então centrifugado a $2500 \mathrm{rpm}$ por $10 \mathrm{~min}$ em temperatura ambiente. A seguir, o soro foi aliquotado em frações de $250 \mu \mathrm{L}$ e estocado para posterior análise. A atividade sérica da CK-Total (Siemens Medical Systems, Alemanha) foi mensurada em laboratório de análises sanguíneas local (Laboratórios Sabin, Brasil). 


\subsection{TEMPERATURA DA PELE, CONFORTO E SENSAÇÃO TÉRMICA}

O conforto térmico foi relatado através de uma escala contendo cinco valores numéricos, onde "0" descrevia uma sensação "confortável" e "4" descrevia "extremamente desconfortável". A sensação térmica foi reportada em uma escala contendo nove valores numéricos, onde "-4" descreveu "muito frio" e "+4" "muito quente" (31). A temperatura da região anterior da coxa foi medida com um termômetro infravermelho (Fluke, 566, China) em um ponto previamente demarcado. O termômetro foi posicionado perpenticularmente e o mais próximo possível da pele, porém sem tocála. As medidas de temperatura da pele, conforto e sensação térmicas foram obtidas antes e a cada cinco minutos durante o procedimento de IAG.

\subsection{ANÁLISE ESTATÍSTICA}

O teste de Shapiro-Wilks foi utilizado para analizar a distribuição dos dados. Gráficos do tipo Box-plot foram criados para permitir a inspeção de possíveis outliers. Os dados da força muscular, desempenho de salto, e CK (escala logarítmica) tiveram distribuição normal e foram descritos em suas médias e erros-padrão. O DMIT não apresentou distribuição normal e foi reportado pela mediana e intervalos interquartis. Os dados normalmente distribuídos foram analizados usando a ANOVA de modelos mistos. Adicionalmente, forão utilizadas ANOVAs de medidas repetidas para a determinação do momento em que cada variável retornou ao seu respectivo valor de repouso após o exercício. Quando necessário, os graus de liberdade e os valores de $F$ foram corrigidos através do método de Greenhouse e Geisser. Para os dados de DMIT foi utilizado o teste não paramétrico de Kruskal-Wallis para verificar possíveis diferenças entre os grupos, enquanto que o teste de Mann-Whitney foi utilizado para comparar a sensação térmica, 
conforto térmico, e a temperatura da pele dos grupos submetidos a IAG. O software SPSS (Statistical Package for Social Sciences) versão 23.0 (IBM, USA) foi utilizado para as análises e foi considerada a probabilidade de $5 \%(p=0.05)$. Uma análise retrospectiva do poder amostral (1- $\beta$ ) foi realizada através do software $G^{*}$ Power (version 3.1.2). 


\section{RESULTADOS}

\subsection{FORÇA MUSCULAR}

Os valores de torques dos extensores do joelho para cada grupo experimental são apresentados na Figura 3. O protocolo de exercício reduziu o torque $[(F 3.77,147.11)=$ 87.70, $p=0.001, f=0.18$ ], o qual foi principalmente observado no momento pós-exercício (66.5\% dos valores pré-exercício). O torque gradualmente retornou na direção dos valores pré-exercício, porém foi complemente restaurado apenas após $168 \mathrm{~h}$. Não houve diferença entre os grupos experimentais $[F(7.54,147.11)=0.64, p=0.73$, power $(1-\beta)=$ $0.28]$.

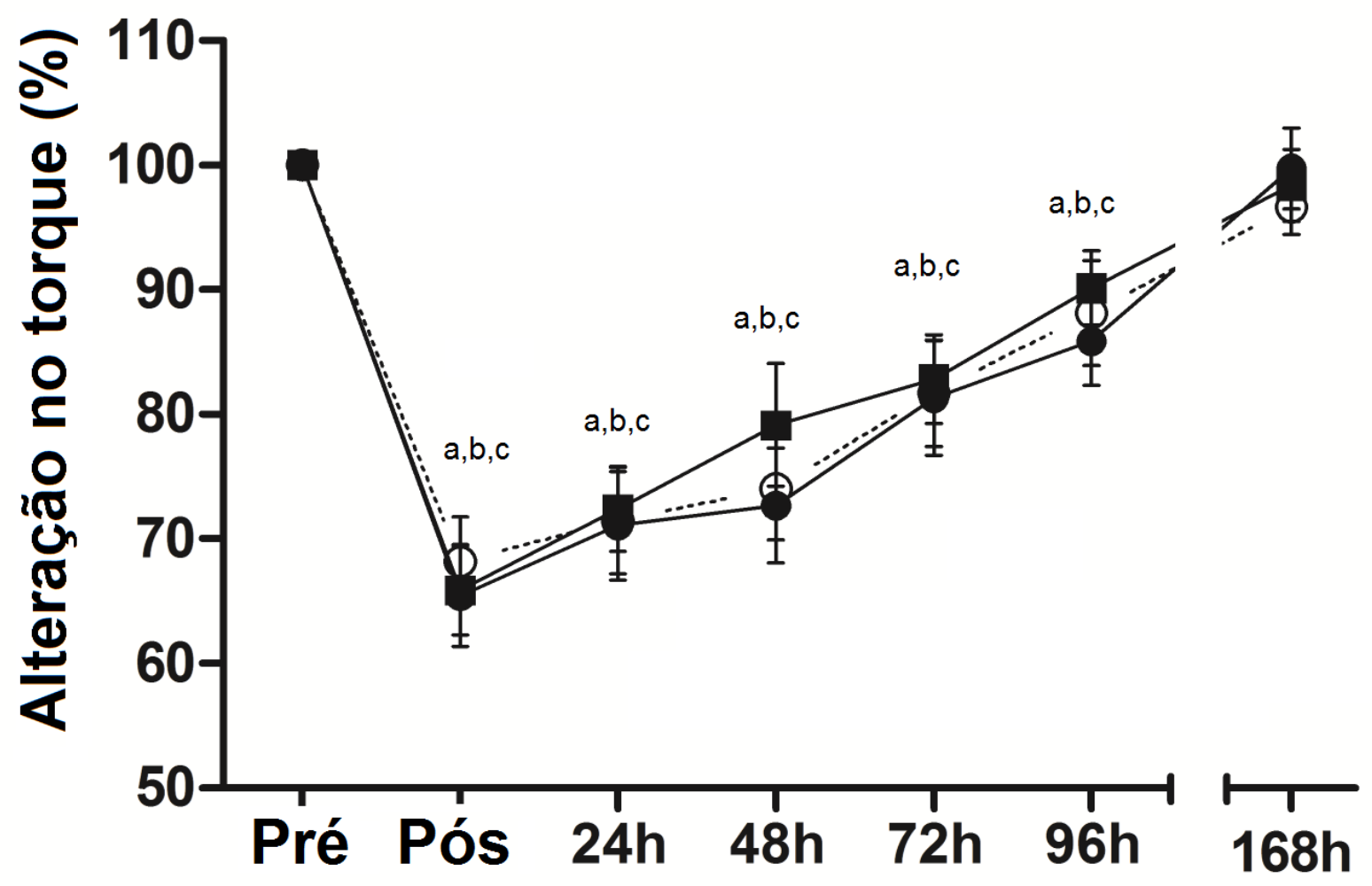

Figura 3. Alterações percentuais (media $\pm E P M$ ) no torque dos extensores do joelho basal (Pré), imediatamente após (Pós), de $24 \mathrm{~h}$ a $96 \mathrm{~h}$, e 168h (uma semana) pós-exercício. Imersão em água gelada $(\mathrm{IAG})$ a $5^{\circ} \mathrm{C}(\mathrm{\circ})$; IAG a $15^{\circ} \mathrm{C}(\bullet)$; e grupo controle (a). a significa diferente do pré para IAG a $15{ }^{\circ} \mathrm{C}$; ${ }^{\mathrm{b}}$ diferente do pré para IAG a $5 \stackrel{\circ}{\circ} \mathrm{C} ;{ }^{c}$ diferente do pré para o grupo controle. 


\subsection{PERFORMANCE MUSCULAR}

O desempenho do SCM para cada um dos grupos experimentais é apresentado na Figura 4. O protocolo de exercícios reduziu o desempenho do SCM $[(F 3.25,81.23)=$ 11.08, $\mathrm{p}=0.001, f=0.31$. A queda no desempenho imediatamente pós-exercício foi similar entre os grupos $(84,1 \%-87,7 \%)$, porém eles recuperaram o desempenho diferentemente ao longo dos dias. G5 e GC tiveram uma segunda queda no desempenho 48h pós-exercício, enquanto que o G15 demonstrou uma recuperação linear do desempenho. G15 então demonstrou valores próximos àqueles observados pré-exercício após $72 \mathrm{~h}$ ( $\mathrm{p}=0.11$ ), e o G5 apresentou valores similares aos pré-exercício em 96h após $(p=0.28)$. GC não recuperou o desempenho em nenhum dos momentos investigados ( $p$ $<0.05)$.

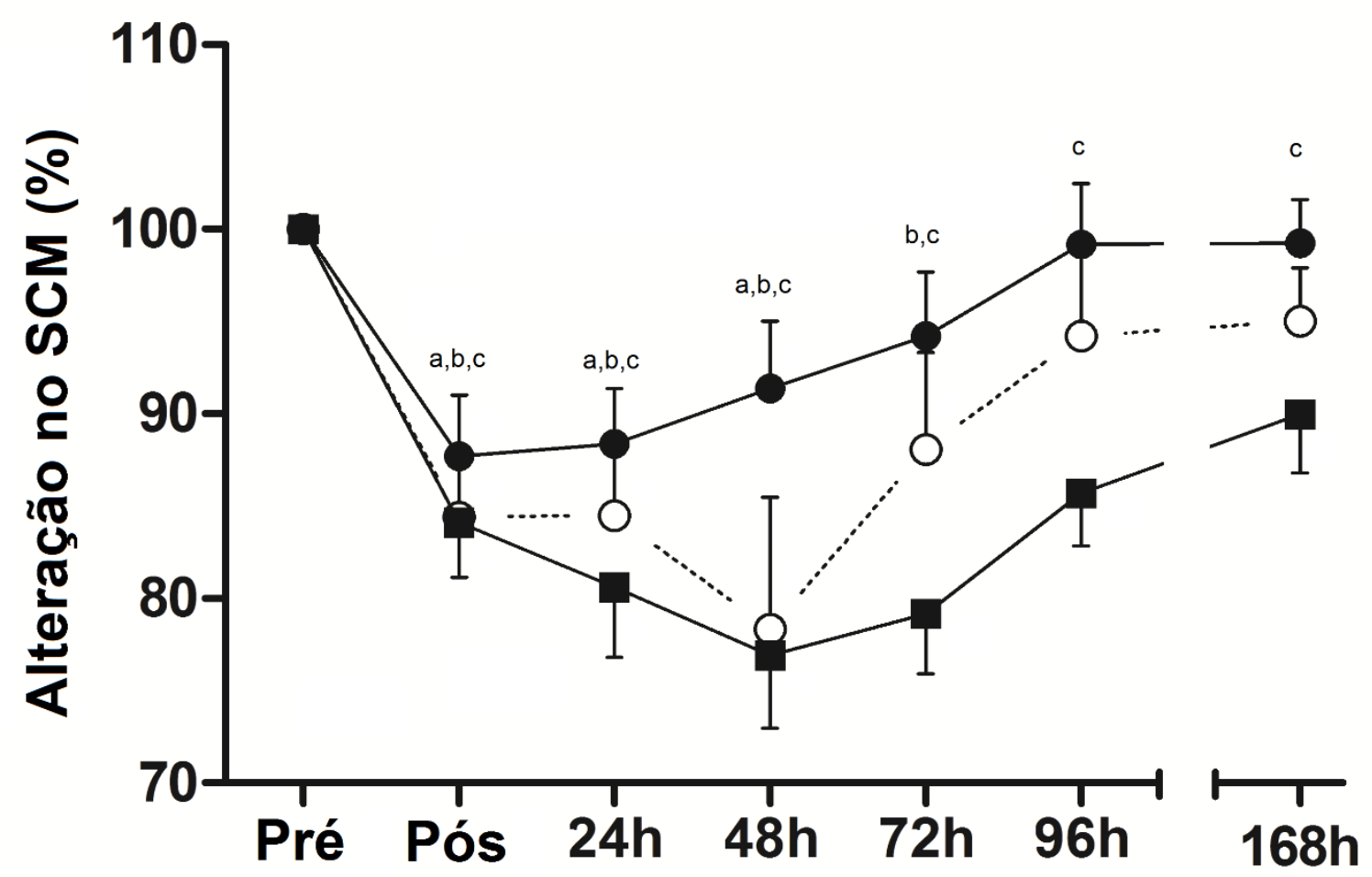

Figura 4. Alterações percentuais (media \pm EPM) do desempenho no salto com contramovimento (SCM) basal (Pré), imediatamente após (Pós), de $24 \mathrm{~h}$ a 96h, e 168h (uma semana) pós-exercício. Imersão em água gelada (IAG) a $5^{\circ} \mathrm{C}(\circ)$; IAG a $15^{\circ} \mathrm{C}(\bullet)$; e grupo controle $(\bullet) .{ }^{a}$ significa diferente do pré para IAG a $15^{\circ} \mathrm{C} ;{ }^{b}$ diferente do pré para IAG a $5^{\circ} \mathrm{C}$; ${ }^{\mathrm{c}}$ diferente do pré para o grupo controle. 


\subsection{DOR MUSCULAR DE INÍCIO TARDIO}

A percepção de dor foi relatada durante: 1) sentar-e-levantar de uma cadeira, e 2) durante as contrações isométricas máximas. Os resultados são apresentadas na Figura 5. A dor gradualmente aumentou e atingiu seu pico em 48h pós-exercício. Embora não tenha havido diferenças entre os grupos experimentais em nenhum dos momentos $(p>$ $0.05), \mathrm{G} 15$ tendeu a apresentar menor dor em $24 \mathrm{~h}$ pós-exercício quando comparado ao GC. As medianas de dor em 24 h durante sentar-e-levantar foi reportada em 4,6 para G15 contra 5,8 de $G C(p=0.07)$. Durante a contração máxima foi reportada 3,3 contra 4,9 para G15 e GC, respectivamente $(p=0.06)$.
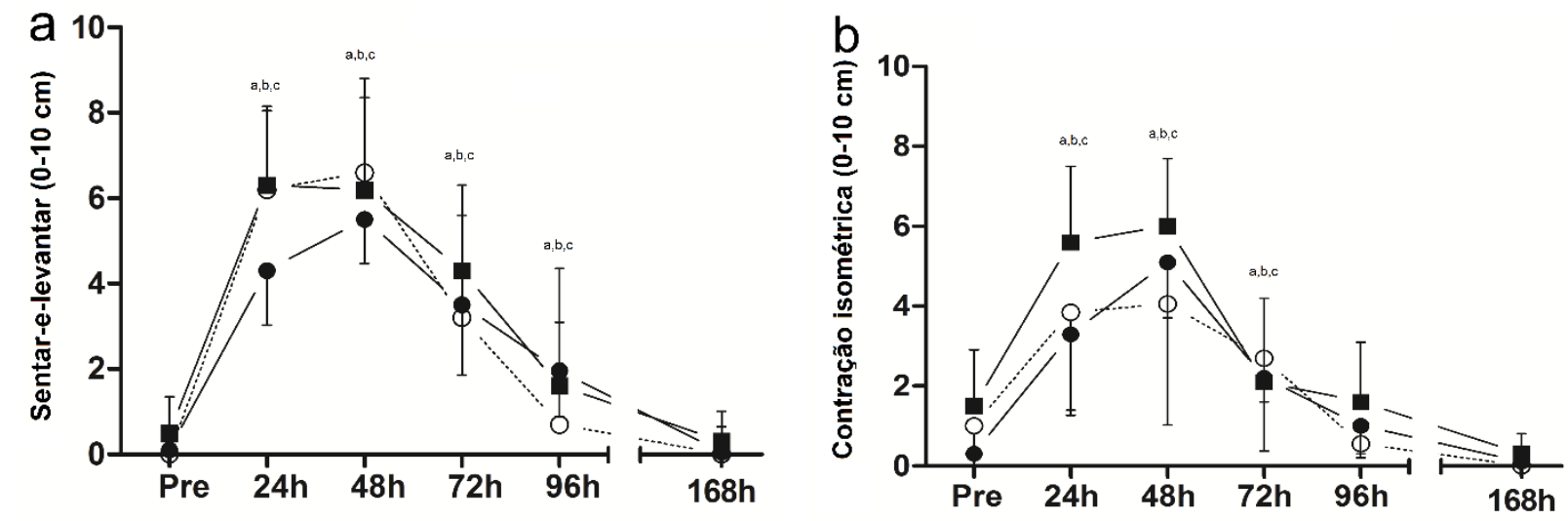

Figura 5. Alterações (medianas \pm intervalos interquartis) na percepção de dor muscular durante sentar-elevantar (a) e durante contração voluntária máxima (b) mensuradas pré, 24h a 96h, e 168h (uma semana) pós-exercício. Imersão em água gelada (IAG) a $5{ }^{\circ} \mathrm{C}(\circ)$; IAG a $15^{\circ} \mathrm{C}(\bullet)$; e grupo controle (घ)..$^{a}$ significa diferente do pré para IAG a $15{ }^{\circ} \mathrm{C}$; ${ }^{b}$ diferente do pré para IAG a $5{ }^{\circ} \mathrm{C} ;{ }^{\circ}$ diferente do pré para 0 grupo controle. 


\subsection{CREATINE QUINASE}

As atividades séricas da CK são apresentadas na Figura 6. O protocolo de exercício aumentou as concentrações séricas da CK $[(F 2.19,63.48)=40.62, p=0.001$, $f=0.33]$ nos dias seguintes ao exercício. No entanto, G15 apresentou níveis de CK próximos dos pré-exercício ( $\mathrm{p}=0.24$ ) após $72 \mathrm{~h}$, enquanto que os níveis de CK para ambos G5 e GC não retornaram aos valores basais em nenhum dos momentos mensurados posteriormente $(p<0.05)$.

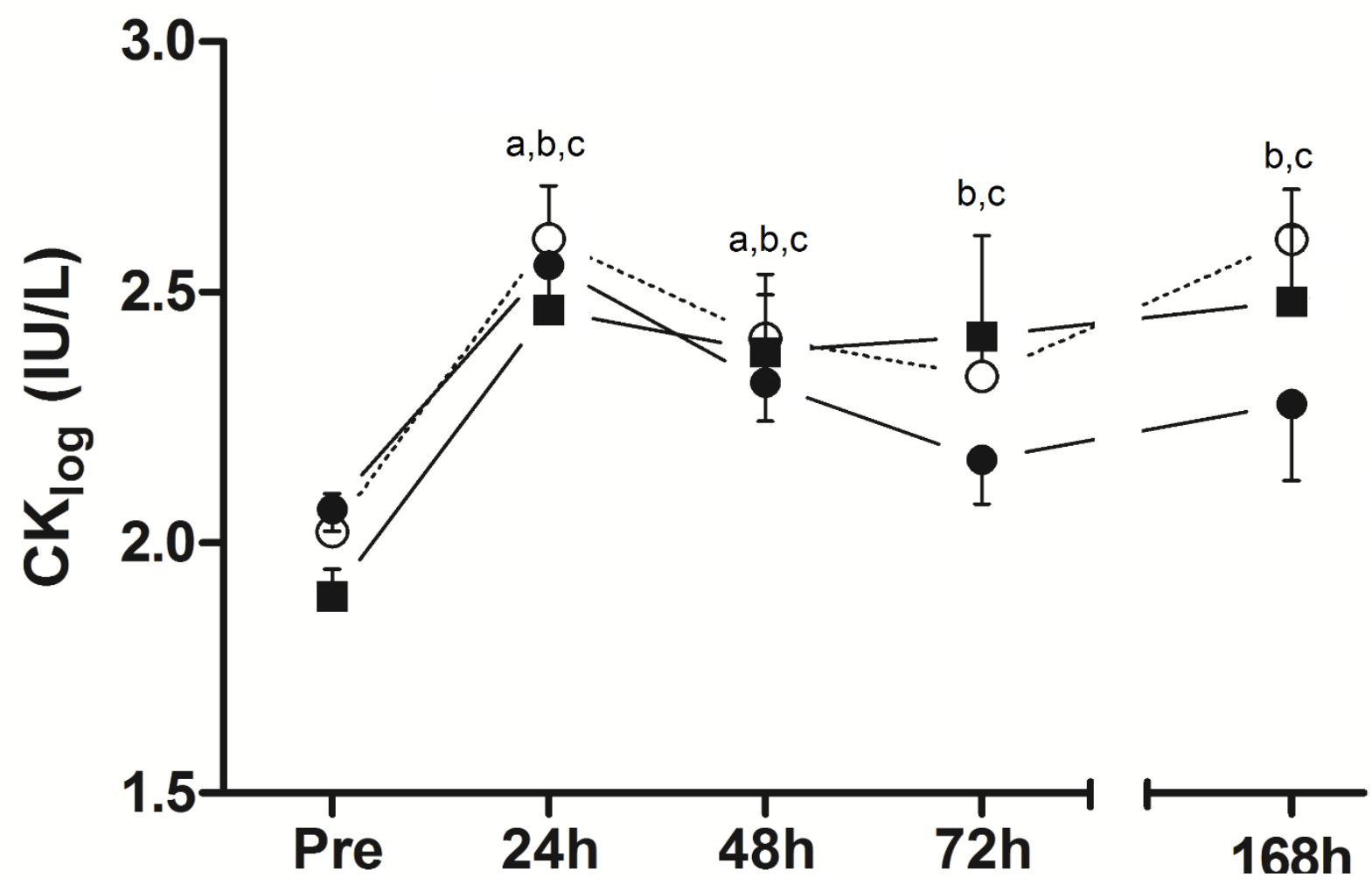

Figura 6. Atividade sérica da creatina quinase (CK) (média \pm EPM, em escala logarítimica) basal (Pré), de $24 \mathrm{~h}$ a $72 \mathrm{~h}$, e $168 \mathrm{~h}$ (uma semana) pós-exercício. Imersão em água gelada (IAG) a $5{ }^{\circ} \mathrm{C}(\mathrm{O})$; IAG a $15^{\circ} \mathrm{C}(\bullet)$; e grupo controle ( $\mathbf{\square}){ }^{\text {a }}$ significa diferente do pré para IAG a $15{ }^{\circ} \mathrm{C}$; ${ }^{b}$ diferente do pré para IAG a $5{ }^{\circ} \mathrm{C}$; ${ }^{\mathrm{c}}$ diferente do pré para o grupo controle. 


\subsection{TEMPERATURA DA PELE, CONFORTO E SENSAÇÃO TÉRMICA}

Conforto térmico, sensação térmica, e temperature da pele dos grupos submetidos a IAG são apresentadas na Figura 7. Ambos os grupos G5 e G15 demonstraram uma menor temperatura da pele comparado com os valores basais ao longo de todo o tratamento $(p<0.001)$, os participantes do G5 demonstraram menor temperatura da pele do que aqueles do G15 ( $p=0.001)$. Os indivíduos do G5 relataram maior desconforto térmico após cinco e 10 minutos, e também relataram sensação térmica de maior frio cinco minutos após de imersão $(p<0.05)$.
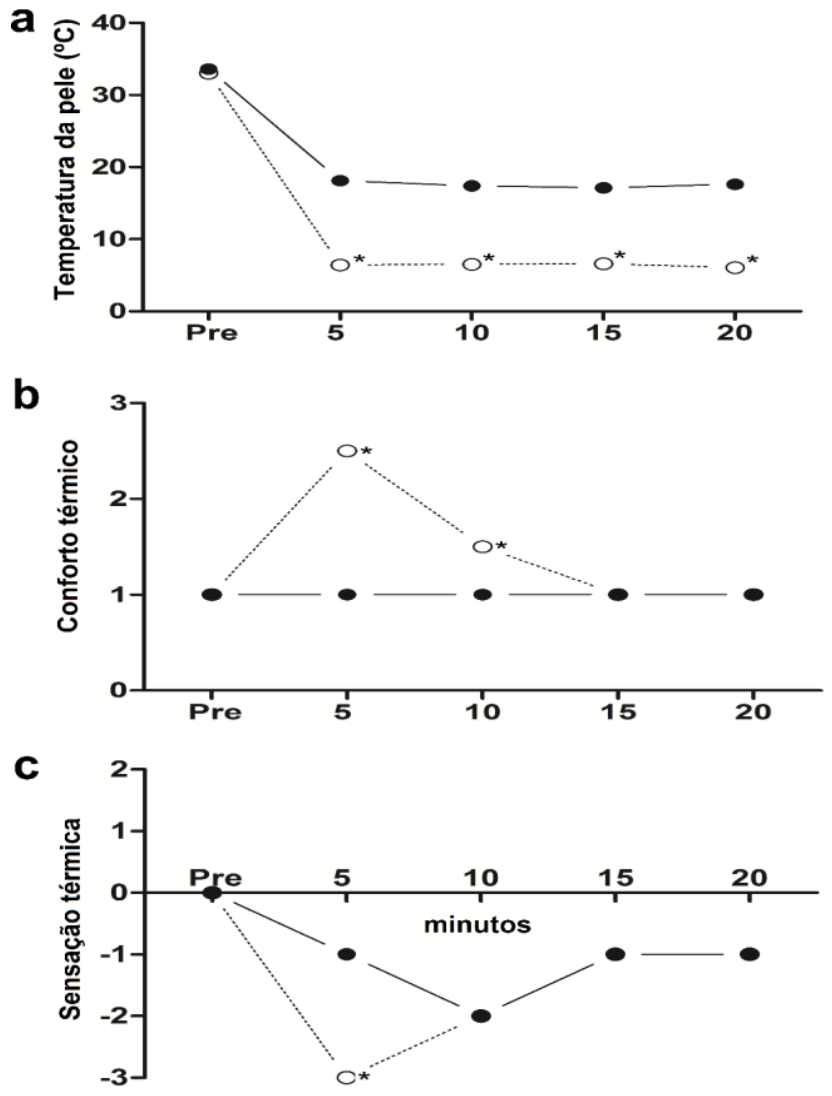

Figure 7. Temperatura da pele (a), conforto térmico (b), e sensação térmica (c) medidos antes (Pré) e a cada cinco minutos ao longo da aplicação de imersão em água gelada (IAG). IAG a $5^{\circ} \mathrm{C}(\circ)$; IAG a $15^{\circ} \mathrm{C}(\bullet) .{ }^{*}$ diferença entre os grupos. 


\section{DISCUSSÃO}

O principal achado do presente estudo foi que ambos os protocolos de IAG foram efetivos em acelerar a recuperação do desempenho do SCM, mas não o torque isométrico. Houve uma divergência entre o efeito da IAG sobre a máxima força contrátil, a qual é comumente usada como principal indicador de 'dano muscular', e o desempenho durante o SCM, que envolve o CAE. Foi inicialmente hipotetizado que o protocolo com maior capacidade de resfriamento $\left(5^{\circ} \mathrm{C}\right)$ produziria resultados superiores $(4,5)$; no entanto, IAG a 15을 demonstrou ser mais benéfica para a recuperação do desempenho do SCM. G15 recuperou o desempenho do SCM linearmente ao longo do tempo, enquando que G5 demonstrou uma segunda queda no desempenho em $48 \mathrm{~h}$ pósexercício. Os indivíduos do G15 também demonstraram um melhor perfil de recuperação através da resposta da CK quando eles demonstraram valores similares ao basais em $72 h$ pós-exercício.

Estudos têm examinado os efeitos de diferentes protocolos de IAG na recuperação da função muscular após o DMIE. Alguns estudos têm demonstrado benefício da IAG na recuperação pós-exercício (3, 10-12), porém outros não (13-15). Esta discrepância parece ser relacionada com a forma a qual a função muscular tem sido avaliada. Os estudos que não demonstraram benefícios da IAG somente mediram a função muscular por meio do torque dos extensors do joelho, assumindo este resultado como sendo representativo da função muscular. No entanto, parece que a força isométrica isoladamente não representa a capacidade total do músculo de produzir trabalho. De fato, tem sido sugerido, a partir de um ponto de vista funcional, que a função muscular deve ser avaliada numa perspectiva mais ambrangente, envolvendo uma maior participação do complexo músculo-tendão $(67,68)$. O desempenho durante o SCM, o qual é altamente dependente da capacidade miotendínea de produzir trabalho, parece fornecer uma melhor visão do funcionamento do sistema muscular esquelético. Tem sido destacado que a pré-ativação, a qual ocorre imediatamente antes da fase propulsiva do salto, contribui para o desenvolvimento da força pela combinação de diversas propriedades

neuromusculares. Propriedades estas que incluem: (i) maior tempo para o 
desenvolvimento da força, (ii) armazenamento e utilização da energia elástica, (iii) potenciação da maquinaria contrátil do músculo, e (iv) ativação de reflexos proprioceptivos $(3,68)$. Dessa forma, a aplicação da IAG no tratamento do DMIE pode influenciar tais aspectos e consequentemente favorecendo uma melhor recuperação em tarefas dependentes do CAE do que a recuperação da força isométrica isoladamente.

Um dos benefícios que tem sido argumentados para a utilização da crioterapia é que esta seria capaz de evitar o dano secondário do tecido adjacente à área da lesão. Uma explicação para o dano secundário considera que a ação das células do sistema imunitário podem agravar o dano através da ação de enzimas lisossomais, degradando células debris e consequentemente o tecido saudável ao seu redor (5). Uma vez que a crioterapia tem sido largamente associada com uma atenuada resposta inflamatória (2, 5) e o dano oxidativo (69), seus efeitos terapêuticos poderiam então melhor controlar uma possível resposta inflamatória exacerbada. Isto poderia teoricamente ser traduzido em uma menor área de dano, assim requerendo menor tempo para a sua regeneração.

É geralmente assumido que protocolos de IAG com maior capacidade de resfriamento, tal como usando água resfriada a $5{ }^{\circ} \mathrm{C}$ poderia melhor facilitar a restauração do desempenho que protocolos com menor capacidade de resfriamento $(4,5)$. Todavia, a recuperação do desempenho durante o $\mathrm{SCM}$, bem como dos níveis séricos de $\mathrm{CK}$ foram mais rápidas no G15 do que no G5. Adicionalmente, apesar de não ter diferença significativa, a percepção de dor muscular em $24 \mathrm{~h}$ pós-exercício foi menor naqueles que foram alocados no G15 comparados com GC. Uma possível explicação é que a água mais fria pode ter sido um estresse adicional para o organismo. Lee e colaboradores (70) e White e colaboradores (3) encontraram que protocolos de IAG com maior capacidade de resfriamento, seja pela maior duração da aplicação ou seja por usar água com menor temperatura, na verdade podem exacerbar a resposta pró-inflamatória. De fato, Tseng e colaboradores (71) reportaram efeitos detrimentais da crioterapia sobre a recuperação após dano muscular quando múltiplas aplicações com pacote de gelo foram realizadas. Além disso, os diferentes padrões de recuperação da função muscular demonstrados entre os grupos durante o SCM parecem indicar que houve um maior benefício do protocolo usando água a $15^{\circ} \mathrm{C}$. A recuperação do SCM de ambos G5 e GC demonstrou um comportamento bimodal, ou seja, o desempenho do SCM declinou imediatamente 
após o exercício, então declinou ainda mais, atingindo o piores valores $48 \mathrm{~h}$ pós-exercício. Embora G5 tenha demonstrado uma recuperação mais rápida que GC, o segundo declínio no desempenho sugere que possa haver alguma relação com uma resposta inflamatória exarcebada (68), porém isto deve ser explicitamente examinado em estudos futuros.

Embora a habilidade de reduzir a dor muscular tenha sido frequentemente atribuída a crioterapia $(6,8,9)$, ainda existem algumas incertezas a este respeito. No presente estudo, nós apenas observamos uma tendência para uma menor dor muscular em 24h pós-exercício. A ausência de um efeito mais substancial no presente estudo talvez deve-se ao fato que nós realizamos apenas uma imersão. Também pode ser considerado que a alta variabilidade intra-sujeitos pode ter mascarado algum potencial benefício da IAG. De fato, Skurvydas e colaboradores (10) demonstraram que IAG a 15 C significativamente atenuou a DMIT. Estes autores aplicaram IAG em múltiplos momentos $(0,4,8,24 \mathrm{~h})$ utilizando um duração relativamente mais longa (2 série de 15 minutos cada). Eles também utilizaram os mesmos sujeitos para intervenção e controle (crossover design), o qual reconhecidamente reduz a variabilidade intra-sujeitos. Enquanto que um delineamento crossover nesta situação em particular não seja recomendado devido o efeito da carga repetida, o efeito de uma única aplicação versus múltiplas aplicações de IAG requer futuras investigações. 


\section{CONCLUSÃO}

Esta investigação objetivou descrever uma limitação, descrita em prévio estudo (8), relacionada a escolha da temperatura da água em protocolos de IAG. Enquanto ambos protocolos de IAG foram associados à uma melhor recuperação do SCM, com resultado mais favorável para $15 \stackrel{\circ}{ } \mathrm{C}$ de temperatura, nenhum benefício foi observado da IAG na recuperação da força isométrica. Esta discrepância sugere que IAG pode recuperar aspectos associados ao $\mathrm{CAE}$, tais como utilização da energia elástica, ativação de reflexos proprioceptores, maior tempo para produzir a força e/ou potenciação da produção de força. Além disso, a controvérsia reportada por prévios estudos (3, 10-15) sobre os efeitos da IAG na recuperação da função muscular possa ser devido a maneira a qual a função muscular tem sido avaliada após o DMIE. Futuras investigações poderiam investigar os mecanismos responsáveis pelo benefício da IAG em atividades envolvendo CAE. 


\section{REFERÊNCIAS}

1. Paulsen G, Mikkelsen UR, Raastad T, Peake JM. Leucocytes, cytokines and satellite cells: what role do they play in muscle damage and regeneration following eccentric exercise? Exerc Immunol Rev. 2012;18:42-97.

2. Vieira Ramos G, Pinheiro CM, Messa SP, Delfino GB, Marqueti Rde C, Salvini Tde $F$, et al. Cryotherapy Reduces Inflammatory Response Without Altering Muscle Regeneration Process and Extracellular Matrix Remodeling of Rat Muscle. Sci Rep. 2016;6:18525.

3. White GE, Rhind SG, Wells GD. The effect of various cold-water immersion protocols on exercise-induced inflammatory response and functional recovery from highintensity sprint exercise. Eur J Appl Physiol. 2014;114(11):2353-2367.

4. Merrick MA, Jutte LS, Smith ME. Cold Modalities With Different Thermodynamic Properties Produce Different Surface and Intramuscular Temperatures. J Athl Train. 2003;38(1):28-33.

5. Merrick MA. Secondary injury after musculoskeletal trauma: a review and update. J Athl Train. 2002;37(2):209-217.

6. Bleakley C, McDonough S, Gardner E, Baxter GD, Hopkins JT, Davison GW. Coldwater immersion (cryotherapy) for preventing and treating muscle soreness after exercise. Cochrane Database Syst Rev. 2012;2:CD008262.

7. Wilcock IM, Cronin JB, Hing WA. Physiological response to water immersion: a method for sport recovery? Sports Med. 2006;36(9):747-765.

8. Leeder J, Gissane C, van Someren K, Gregson W, Howatson G. Cold water immersion and recovery from strenuous exercise: a meta-analysis. $\mathrm{Br} J$ Sports Med. 2012;46(4):233-240.

9. Hohenauer E, Taeymans J, Baeyens JP, Clarys P, Clijsen R. The Effect of PostExercise Cryotherapy on Recovery Characteristics: A Systematic Review and MetaAnalysis. PLoS One. 2015;10(9):e0139028.

10. Skurvydas A, Sipaviciene S, Krutulyte G, Gailiuniene A, Stasiulis A, Mamkus G, et al. Cooling leg muscles affects dynamics of indirect indicators of skeletal muscle damage. J Back Musculoskeletal. 2006;19:141-151. 
11. Vaile J, Halson S, Gill N, Dawson B. Effect of cold water immersion on repeat cycling performance and thermoregulation in the heat. J Sports Sci. 2008;26(5):431-440.

12. King M, Duffield R. The effects of recovery interventions on consecutive days of intermittent sprint exercise. J Strength Cond Res. 2009;23(6):1795-1802.

13. Goodall S, Howatson G. The effects of multiple cold water immersions on indices of muscle damage. J Sport Sci Med. 2008;7:235-241.

14. Jakeman JR, Macrae R, Eston R. A single 10-min bout of cold-water immersion therapy after strenuous plyometric exercise has no beneficial effect on recovery from the symptoms of exercise-induced muscle damage. Ergonomics. 2009;52(4):456-460.

15. Sellwood KL, Brukner P, Williams D, Nicol A, Hinman R. Ice-water immersion and delayed-onset muscle soreness: a randomised controlled trial. $\mathrm{Br} J$ Sports Med. 2007;41(6):392-397.

16. Knight KL. Cryotherapy in sports injury management. Champaign, IL: Human Kinetics; 1995.

17. Rymaszewska J, Tulczynski A, Zagrobelny Z, Kiejna A, Hadrys T. Influence of whole body cryotherapy on depressive symptoms - preliminary report. Acta Neuropsychiatr. 2003;15(3):122-128.

18. Knight KL. Effects of hypothermia on inflammation and swelling. Athl Train. 1976;11:7-10.

19. Vieira A, Oliveira AB, Costa JR, Herrera E, Salvini TF. Cold modalities with different thermodynamic properties have similar effects on muscular performance and activation. Int J Sports Med. 2013;34(10):873-880.

20. Kennet J, Hardaker N, Hobbs S, Selfe J. Cooling efficiency of 4 common cryotherapeutic agents. J Athl Train. 2007;42(3):343-348.

21. Ferreira-Junior JB, Bottaro M, Loenneke JP, Vieira A, Vieira CA, Bemben MG. Could whole-body cryotherapy (below -100 degrees $C$ ) improve muscle recovery from muscle damage? Front Physiol. 2014;5:247.

22. Banfi G, Lombardi G, Colombini A, Melegati G. Whole-body cryotherapy in athletes. Sports Med. 2010;40(6):509-517. 
23. Fonda B, Sarabon N. Effects of whole-body cryotherapy on recovery after hamstring damaging exercise: a crossover study. Scand J Med Sci Sports. 2013;23(5):e270-278.

24. Morgan DL. New Insights into the Behavior of Muscle during Active Lengthening. Biophysical Journal. 1990;57(2):209-221.

25. Clarkson PM, Hubal MJ. Exercise-induced muscle damage in humans. Am J Phys Med Rehabil. 2002;81(11 Suppl):S52-69.

26. Peake J, Nosaka K, Suzuki K. Characterization of inflammatory responses to eccentric exercise in humans. Exerc Immunol Rev. 2005;11:64-85.

27. Proske U, Morgan DL. Muscle damage from eccentric exercise: mechanism, mechanical signs, adaptation and clinical applications. J Physiol. 2001;537(Pt 2):333-345.

28. Proske U, Allen TJ. Damage to skeletal muscle from eccentric exercise. Exerc Sport Sci Rev. 2005;33(2):98-104.

29. Smith LL, Anwar A, Fragen M, Rananto C, Johnson R, Holbert D. Cytokines and cell adhesion molecules associated with high-intensity eccentric exercise. European Journal of Applied Physiology. 2000;82(1-2):61-67.

30. Costello JT, Baker PRA, Minett GM, Bieuzen F, Stewart IB, Bleakley C. Wholebody cryotherapy (extreme cold air exposure) for preventing and treating muscle soreness after exercise in adults. Cochrane Database of Syst Rev. 2013;10:CD010789.

31. Costello JT, Culligan K, Selfe J, Donnelly AE. Muscle, skin and core temperature after -110 degrees $\mathrm{C}$ cold air and 8 degrees c water treatment. PLoS One. 2012;7(11):e48190.

32. Poppendieck W, Faude O, Wegmann M, Meyer T. Cooling and performance recovery of trained athletes: a meta-analytical review. Int J Sports Physiol Perform. 2013;8(3):227-242.

33. Bleakley CM, Davison GW. What is the biochemical and physiological rationale for using cold-water immersion in sports recovery? A systematic review. Br J Sports Med. 2010;44(3):179-187.

34. Versey NG, Halson SL, Dawson BT. Water immersion recovery for athletes: effect on exercise performance and practical recommendations. Sports Med. 2013;43(11):11011130. 
35. Ferreira-Junior JB, Bottaro M, Vieira CA, Soares SR, Vieira A, Cleto VA, et al. Effects of Partial-body Cryotherapy (- 110 degrees C) on Muscle Recovery between Highintensity Exercise Bouts. International Journal of Sports Medicine. 2014.

36. Ferreira-Junior JB, Bottaro M, Vieira A, Siqueira AF, Vieira CA, Durigan JL, et al. One session of partial-body cryotherapy (-110 degrees C) improves muscle damage recovery. Scand J Med Sci Sports. 2014.

37. Pritchard KA, Saliba SA. Should athletes return to activity after cryotherapy? J Athl Train. 2014;49(1):95-96.

38. Schniepp J, Campbell TS, Powell KL, Pincivero DM. The effects of cold-water immersion on power output and heart rate in elite cyclists. J Strength Cond Res. 2002;16(4):561-566.

39. Drinkwater E. Effects of peripheral cooling on characteristics of local muscle. Med Sport Sci. 2008;53:74-88.

40. Peiffer JJ, Abbiss CR, Watson G, Nosaka K, Laursen PB. Effect of a 5-min coldwater immersion recovery on exercise performance in the heat. $\mathrm{Br} J$ Sports Med. 2010;44(6):461-465.

41. Ascensao A, Leite M, Rebelo AN, Magalhaes S, Magalhaes J. Effects of cold water immersion on the recovery of physical performance and muscle damage following a oneoff soccer match. J Sports Sci. 2011;29(3):217-225.

42. Bailey DM, Erith SJ, Griffin PJ, Dowson A, Brewer DS, Gant N, et al. Influence of cold-water immersion on indices of muscle damage following prolonged intermittent shuttle running. J Sports Sci. 2007;25(11):1163-1170.

43. Brophy-Williams N, Landers G, Wallman K. Effect of immediate and delayed cold water immersion after a high intensity exercise session on subsequent run performance. J Sports Sci Med. 2011;10(4):665-670.

44. Crowe MJ, O'Connor D, Rudd D. Cold water recovery reduces anaerobic performance. Int J Sports Med. 2007;28(12):994-998.

45. Heyman E, B DEG, Mertens I, Meeusen R. Effects of four recovery methods on repeated maximal rock climbing performance. Med Sci Sports Exerc. 2009;41(6):13031310. 
46. Higgins TR, Heazlewood IT, Climstein M. A random control trial of contrast baths and ice baths for recovery during competition in U/20 rugby union. $J$ Strength Cond Res. 2011;25(4):1046-1051.

47. Ingram J, Dawson B, Goodman C, Wallman K, Beilby J. Effect of water immersion methods on post-exercise recovery from simulated team sport exercise. J Sci Med Sport. 2009;12(3):417-421 .

48. Lane KN, Wenger HA. Effect of selected recovery conditions on performance of repeated bouts of intermittent cycling separated by 24 hours. J Strength Cond Res. 2004;18(4):855-860.

49. Montgomery PG, Pyne DB, Hopkins WG, Dorman JC, Cook K, Minahan CL. The effect of recovery strategies on physical performance and cumulative fatigue in competitive basketball. J Sports Sci. 2008;26(11):1135-1145.

50. Parouty J, Al Haddad H, Quod M, Lepretre PM, Ahmaidi S, Buchheit M. Effect of cold water immersion on 100-m sprint performance in well-trained swimmers. Eur J Appl Physiol. 2010;109(3):483-490.

51. Peiffer JJ, Abbiss CR, Nosaka K, Peake JM, Laursen PB. Effect of cold water immersion after exercise in the heat on muscle function, body temperatures, and vessel diameter. J Sci Med Sport. 2009;12(1):91-96.

52. Pournot H, Bieuzen F, Duffield R, Lepretre PM, Cozzolino C, Hausswirth C. Short term effects of various water immersions on recovery from exhaustive intermittent exercise. Eur J Appl Physiol. 2011;111(7):1287-1295.

53. Rowsell GJ, Coutts AJ, Reaburn P, Hill-Haas S. Effect of post-match cold-water immersion on subsequent match running performance in junior soccer players during tournament play. J Sports Sci. 2011;29(1):1-6.

54. Vaile J, Halson S, Gill N, Dawson B. Effect of hydrotherapy on recovery from fatigue. Int J Sports Med. 2008;29(7):539-544.

55. Vaile J, Halson S, Gill N, Dawson B. Effect of hydrotherapy on the signs and symptoms of delayed onset muscle soreness. Eur J Appl Physiol. 2008;102(4):447-455.

56. Vaile J, O'Hagan C, Stefanovic B, Walker M, Gill N, Askew CD. Effect of cold water immersion on repeated cycling performance and limb blood flow. $\mathrm{Br} J$ Sports Med. 2011;45(10):825-829. 
57. Yeargin SW, Casa DJ, McClung JM, Knight JC, Healey JC, Goss PJ, et al. Body cooling between two bouts of exercise in the heat enhances subsequent performance. $J$ Strength Cond Res. 2006;20(2):383-389.

58. Broatch JR, Petersen A, Bishop DJ. Postexercise cold water immersion benefits are not greater than the placebo effect. Med Sci Sports Exerc. 2014;46(11):2139-2147.

59. Koch AJ, Pereira R, Machado $M$. The creatine kinase response to resistance exercise. J Musculoskelet Neuronal Interact. 2014;14(1):68-77.

60. Nosaka K, Clarkson PM. Variability in serum creatine kinase response after eccentric exercise of the elbow flexors. Int J Sports Med. 1996;17(2):120-127.

61. Eston RG, Finney S, Baker S, Baltzopoulos V. Muscle tenderness and peak torque changes after downhill running following a prior bout of isokinetic eccentric exercise. $J$ Sports Sci. 1996;14(4):291-299.

62. Gunst JJ, Langlois MR, Delanghe JR, De Buyzere ML, Leroux-Roels GG. Serum creatine kinase activity is not a reliable marker for muscle damage in conditions associated with low extracellular glutathione concentration. Clin Chem. 1998;44(5):939943.

63. Hody S, Rogister B, Leprince P, Wang F, Croisier JL. Muscle fatigue experienced during maximal eccentric exercise is predictive of the plasma creatine kinase (CK) response. Scand J Med Sci Sports. 2013;23(4):501-507.

64. Miyama M, Nosaka K. Protection against muscle damage following fifty drop jumps conferred by ten drop jumps. J Strength Cond Res. 2007;21(4):1087-1092.

65. Miyama M, Nosaka K. Influence of surface on muscle damage and soreness induced by consecutive drop jumps. J Strength Cond Res. 2004;18(2):206-211 .

66. Ferreira-Junior JB, Bottaro M, Vieira A, Siqueira AF, Vieira CA, Durigan JL, et al. One session of partial-body cryotherapy (-110 degrees $C)$ improves muscle damage recovery. Scand J Med Sci Sports. 2015;25(5):e524-530.

67. Nicol C, Avela J, Komi PV. The stretch-shortening cycle : a model to study naturally occurring neuromuscular fatigue. Sports Med. 2006;36(11):977-999.

68. Byrne C, Twist C, Eston R. Neuromuscular function after exercise-induced muscle damage: theoretical and applied implications. Sports Med. 2004;34(1):49-69. 
69. Puntel GO, Carvalho NR, Amaral GP, Lobato LD, Silveira SO, Daubermann MF, et al. Therapeutic cold: An effective kind to modulate the oxidative damage resulting of a skeletal muscle contusion. Free Radic Res. 2011;45(2):125-138.

70. Lee EC, Watson G, Casa D, Armstrong LE, Kraemer W, Vingren JL, et al. Interleukin-6 responses to water immersion therapy after acute exercise heat stress: a pilot investigation. J Athl Train. 2012;47(6):655-663.

71. Tseng CY, Lee JP, Tsai YS, Lee SD, Kao CL, Liu TC, et al. Topical cooling (icing) delays recovery from eccentric exercise-induced muscle damage. $J$ Strength Cond Res. 2013;27(5):1354-1361. 


\title{
ANEXO A - PARECER DO COMITÊ DE ÉTICA EM PESQUISA EM SERES HUMANOS
}

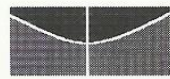 \\ Universidade de Brasília \\ Faculdade de Ciências da Saúde \\ Comitê de Ética em Pesquisa - CEP/FS
}

\section{PROCESSO DE ANÁLISE DE PROJETO DE PESOUISA}

Registro do Projeto no CEP: 243/13

Título do Projeto: "Efeitos de Diferentes Temperaturas de Imersão em ÁGUA Gelada no Desempenho e Recuperação Muscular após dano Muscular Induzido pelo Exercício" Pesquisador Responsável: Amilton Vieira

Data de Entrada: 29/08/2013

Com base na Resolução 466/12, do CNS/MS, que regulamenta a ética em pesquisa com seres humanos, o Comitê de Ética em Pesquisa com Seres Humanos da Faculdade de Ciências da Saúde da Universidade de Brasília, após análise dos aspectos éticos e do contexto técnico-científico, resolveu APROVAR o projeto 243/13 com o título: "Efeitos de Diferentes Temperaturas de Imersão em ÁGUA Gelada no Desempenho e Recuperação Muscular após dano Muscular Induzido pelo Exercício", analisado na $11^{\text {a }}$ Reunião Ordinária, realizada no dia 08 de Outubro de 2013.

$\mathrm{O}$ (a) pesquisador (a) responsável fica, desde já, notificado(a) da obrigatoriedade da apresentação de um relatório semestral e relatório final sucinto e objetivo sobre o desenvolvimento do Projeto, no prazo de 1 (um) ano a contar da presente.

Brasília, 13 de Dezembro de 2013.

Prof. Natant tyonsores Coordenador doleEP-FS/UnB

Comitê de Ética em Pesquisa com Seres Humanos - Faculdade de Ciências da Saúde Universidade de Brasília - Campus Universitário Darcy Ribeiro - CEP: 70.910-900

Telefone: (61)-3107-1947_Email: cepfs@unb.br 


\section{ANEXO B - ACEITE PARA PUBLICAÇÃO DO MANUSCRITO DA TESE}

\section{International Journal of Sports Medicine - Decision on Manuscript ID IJSM-04-2016-} 5597-tt.R2

7 messages

jarduarte@fade.up.pt <jarduarte@fade.up.pt>

Tue, Jun 14,2016 at 12:55 PM

To: acmribeirao@gmail.com

14-Jun-2016

Dear Prof. Vieira:

It is a pleasure to accept your manuscript entitled "THE EFFECT OF WATER TEMPERATURE DURING COLD-WATER IMMERSION ON RECOVERY FROM EXERCISE-INDUCED MUSCLE DAMAGE" in its current form for publication in the International Journal of Sports Medicine.

The galley proofs will be sent to you within a few weeks. After receipt of your printing approval, your article will be published online ahead of print (eFirst) at www.thieme-connect.com. Please note that the date of the online publication is the definite publication date of your article.

Thank you for your fine contribution. On behalf of the Editors of the International Journal of Sports Medicine, we look forward to your continued contributions to the Journal.

Sincerely,

Prof. Jose Duarte

Editor, International Journal of Sports Medicine

jarduarte@fade.up.pt 


\title{
ANEXO C - MANUSCRITO ACEITO PARA PUBLICAÇÃO NO PERIÓDICO INTERNATIONAL JOURNAL OF SPORTS MEDICINE
}

\author{
THE EFFECT OF WATER TEMPERATURE DURING COLD-WATER IMMERSION \\ ON RECOVERY FROM EXERCISE-INDUCED MUSCLE DAMAGE
}

Running Title: Cold water immersion and muscle recovery

\begin{abstract}
This study investigated the effects of $5^{\circ} \mathrm{C}$ and $15^{\circ} \mathrm{C}$ cold-water immersion on recovery from exercise resulting in exercise-induced muscle damage. Forty-two college-aged men performed $5 \times 20$ drop-jumps and were randomly allocated into one of three groups: (1) $5^{\circ} \mathrm{C}$; (2) $15^{\circ} \mathrm{C}$; or (3) control. After exercise, individuals from the cold-water immersion groups had their lower limbs immerged in iced water for 20 min. Isometric knee extensor torque, countermovement jump, muscle soreness, and creatine kinase were measured before, immediately after, 24, 48, 72, 96h and $168 \mathrm{~h}$ post-exercise. There was no between-group difference in isometric strength recovery $(\mathrm{p}=0.73)$. However, countermovement jump recovered quicker in cold-water immersion groups compared to control group $(\mathrm{p}<0.05)$. Countermovement jump returned to baseline after $72 \mathrm{~h}$ in $15^{\circ} \mathrm{C}, 5^{\circ} \mathrm{C}$ group recovered after $96 \mathrm{~h}$ and control did not recovered at any time point measured. Also, creatine kinase returned to baseline at $72 \mathrm{~h}$ and remained stable for all remaining measurements for $15^{\circ} \mathrm{C}$ group, whereas remained elevated past $168 \mathrm{~h}$ in both $5^{\circ} \mathrm{C}$ and control groups. There was a trend toward lower muscle soreness $(\mathrm{p}=0.06)$ in $15^{\circ} \mathrm{C}$ group compared to control at $24 \mathrm{~h}$ post-exercise. The result suggests that cold-water immersion promote recovery of stretch-shortening cycle performance, but not influence the recovery of maximal contractile force.
\end{abstract}


Immersion at warmer temperature may be more effective than colder temperatures promoting recovery from strenuous exercise.

\section{Introduction}

Exercise-induced muscle damage (EIMD) is a common consequence of unaccustomed exercise and/or eccentrically biased exercise which may require several days for the recovery of muscles to their previous functional state [21]. After a bout of damaging exercise, the regeneration of muscle tissues depends on an orchestrated process involving the inflammatory responses [27], which initiates positive feedback mechanisms resulting in an infiltration of inflammatory cells into damaged tissue. Moreover, the magnitude of inflammatory response seems to be modulated by the extent of tissue damage $[21,28]$. While the inflammatory response is fundamental to tissue repair, an excessive response is believed to delay the regenerative process [27, 28]. Therefore, therapeutic strategies aiming to minimise, or indeed 'optimize' the inflammatory response could be beneficial to the regenerative process and ultimately may accelerate muscle recovery.

Cryotherapy, the therapeutic use of cold treatments, is the most commonly used modality for the acute management of musculoskeletal injuries [17]. The most accepted rationales for its use include: (1) the ability to reduce the metabolic rate of tissues, allowing uninjured tissue to survive a post-damage period of ischemia; and (2) protecting surrounding tissue from damaging enzymatic reactions that may accompany damage and inflammatory responses [16, 17]. Cold-water immersion (CWI) is a popular form of cryotherapy and considered one of the most effective for reducing tissue temperature and sustained cooling after removal [10]. CWI has demonstrated antiinflammatory properties, and compared to other forms of cryotherapy (e.g. ice-pack or ice massage) a large volume of the body can be treated easily [28, 29]. It appears as though CWI is an effective strategy for reducing muscle soreness $[2,8,14]$, but its effect on muscle function recovery remains 
inconclusive. There is evidence suggesting that CWI may accelerate recovery $[11,24,26,28]$, whereas other evidence suggests that there is no benefit $[6,9,23]$. These conflicting findings may be attributed to different methodologies utilized. Indeed, there is no established CWI protocol, and important parameter such as water temperature have been poorly controlled [14]. Wilcock et al. [29] suggested that the therapeutic effect of CWI is realised at immersions temperatures of $\leq 15^{\circ} \mathrm{C}$, but it is quite common for researchers to use protocols ranging from $5{ }^{\circ} \mathrm{C}$ [23] to $20^{\circ} \mathrm{C}$ [28]. Recently, White et al. [28] examined the effects of different CWI protocols using water at $10{ }^{\circ} \mathrm{C}$ or $20{ }^{\circ} \mathrm{C}$, which were both applied for 10 or $30 \mathrm{~min}$. The authors found that all protocols had a beneficial effect on countermovement jump (CMJ) performance recovery, except when $20^{\circ} \mathrm{C}$ was used for $10 \mathrm{~min}$. Interestingly, they also observed that CWI protocols of excessive duration may increase, rather than reduce, the inflammatory response [28]. These results suggest that close attention should be placed on these parameters and further studies comparing different water temperatures are still necessary.

Based on a general assumption that colder is better for tissue survival and avoiding secondary damage after injuries $[16,17]$, it could be hypothesized that the protocol with greater cooling capacity, such as $\mathrm{CWI}$ at $5^{\circ} \mathrm{C}$, will produce better outcomes such as allowing performance to return to baseline quicker than CWI at $15^{\circ} \mathrm{C}$. Therefore, the aim of this study was to investigate the effects of $5^{\circ} \mathrm{C}$ and $15^{\circ} \mathrm{C} \mathrm{CWI} \mathrm{protocols} \mathrm{on} \mathrm{recovery} \mathrm{from} \mathrm{exercise} \mathrm{resulting} \mathrm{in} \mathrm{EIMD.}$

\section{Methods}

Participants

An a priori sample size was determined using $\mathrm{G}^{*}$ Power (version 3.1.2) and the following design specifications were taken into account: $\alpha=0.05 ;(1-\beta)=0.8$; effect size $f=0.2$; test family $=\mathrm{F}$ test, and statistical test $=$ analysis of variance $($ ANOVA $)$ repeated measures, within-between 
interaction. The effect size $(f)$ of 0.2 was set to detect 'small' differences, which was based on a recent study that used a similar study design $(f=0.26$; ref [5]). The sample size estimated according to these specifications was 42 subjects. Forty-two college-aged males volunteered to participate. Physical characteristics are shown for each group in Table 1. To be included in the study, subjects must have previously been physically active, participating in mild to moderate intensity physical activities (walking, jogging, agility, or endurance activites) 2-3 times per week. To increase the likelihood of EIMD, individuals who participated in regular strength training or plyometric exercise were excluded from the study. Individuals were also excluded if the thigh skinfold was greater than $20 \mathrm{~mm}$ or knee extensor torque was less than 185 N.m. Individuals participating in the study were considered to be healthy and fit for physical exercise by answering "no" to all PhysicalActivity Readiness Questionnaire (PAR-Q) questions, were not taking any medications, were free of cardiopulmonary or inflammatory diseases, and had no history of adverse reactions to cold temperatures. They were informed of the purpose, procedures, discomforts, risks, and benefits prior to participation and agreed to sign the written informed consent form. The present study was performed in accordance with the ethical standards of this journal [7] and approved by the Institutional Review board (Protocol number 243/13).

Anthropometric measurements

Body mass was assessed with a digital scale to the nearest $0.1 \mathrm{~kg}$ (Lider, Sao Paulo, Brazil), and height was assessed with a stadiometer to the nearest $0.1 \mathrm{~cm}$ (Sanny, Murrhardt, Germany). Body composition was determined according to skinfold thickness with a skinfold caliper (Cescorf, Porto Alegre, Brazil). The Jackson and Pollock equation was used to estimate body density using the chest, abdomen, and thigh skinfolds. Body fat percentage was estimated by the Siri equation to determine fat mass [1]. 


\section{Experimental design}

Figure 1 summarizes the experimental design. Due to the influence of the repeated bout effect on muscle damage levels and time course of recovery [19] a cross-over design was not applied in the present study. The groups were run in parallel, with each group receiving only one form of treatment. During the visit to the laboratory, the forty-two individuals were randomly allocated into one of three groups using the website spreadsheet generator (http://www.randomization.com). The groups were: (1) CWI at $\left.5^{\circ} \mathrm{C}(\mathrm{G} 5, \mathrm{n}=14), 2\right) \mathrm{CWI}$ at $15^{\circ} \mathrm{C}$ $(\mathrm{G} 15, \mathrm{n}=14)$, or 3 ) control $(\mathrm{CG}, \mathrm{n}=14)$. Individuals visited the laboratory on seven occasions. The first visit consisted of familiarization of the experimental procedures (e.g. torque measurement, jump technique) and for anthropometric assessment. Three to seven days after familiarization, individuals performed five sets of 20 drop jumps to induce muscle damage [18]. Four outcome variables were chosen as indirect markers of EIMD: (1) muscle strength, represented by knee extensors isometric torque (2) countermovement jump (CMJ) performance, (3) delayed-onset muscle soreness (DOMS), and (4) serum creatine kinase (CK) activity. These outcome variables were included since they have been often used to investigate the presence of EIMD [14]. They were measured at baseline (Pre), immediately post-exercise (Post), and at 24, 48, 72, 96 and 168 hours post-exercise, given that serum CK activity typically peaks at $48-72 \mathrm{~h}$ post-exercise [12, 15]. Individuals allocated into CWI groups completed a single bout of 20-min of CWI immediately after the Post testing battery, while those from control group remained comfortably seated for the same duration in a quiet and controlled temperature room $\left(21 \pm 1^{\circ} \mathrm{C}\right)$. Volunteers were asked to return to the laboratory at the same time of day ( \pm 1 hour) for all remaining post-intervention testing sessions. They were not allowed to perform any vigorous physical activity or unaccustomed exercise, take medications, or consume any type of supplements during the experimental period. 
In order to keep the assessors blinded during the performance assessments only one researcher had knowledge of the treatment.

\section{Protocol to induce muscle damage}

The exercise protocol consisted of five sets of 20 drop jumps from a $60-\mathrm{cm}$ box with $2 \mathrm{~min}$ of rest between sets. After dropping down from the box and landing on the floor, individuals were instructed to perform a maximally explosive vertical jump upward and then land on the floor. They were instructed to flex their knees to at least at $90^{\circ}\left(0^{\circ}=\right.$ full extension $)$ during all landings and to keep their hands on their hips during the jumps. They were verbally encouraged to exert maximal effort during every repetition. This exercise protocol was chosen since it requires the activation of a large lower-limb muscle mass during contractions that utilize the stretch-shortening cycle (SSC) and produces a response similar to that which might be obtained during high-intensity, multi-joint exercise. Similar exercise protocols have been used in other studies aiming to induce EIMD [5, 6, $9,18]$.

\section{Cold water immersion and passive recovery}

CWI protocols were applied after the participants completed the post-exercise test battery. After the testing assessments CWI were applied for 20 consecutive minutes. Individuals remained seated while immersing their lower limbs ensuring that the iliac crest was fully submerged in the water bath. The water was maintained at the target temperature $\left(5 \pm 1\right.$ or $\left.15 \pm 1^{\circ} \mathrm{C}\right)$ by adding crushed ice as needed. Water temperature was controlled through use of a mercury-in-glass thermometer. Individuals were instructed to perform circular motions with their legs every 2 min to prevent the formation of a warmer boundary layer surrounding the skin. The CG sat quietly at 
room temperature for the same duration. After completing their respective interventions, subjects were allowed to continue with their regular daily activities.

\section{Muscle strength}

Maximal isometric voluntary knee extensor torque at $60^{\circ}\left(0^{\circ}=\right.$ full extension $)$ was measured using a commercial dynamometer (Biodex System 3, Biodex Medical, Inc., Shirley, New York, USA). Individuals were comfortably positioned on the dynamometer seat with belts fastened across the trunk and pelvis to minimize body movements that could affect torque output. The lateral epicondyle of the femur bone was aligned to the dynamometer's axis and the chair and dynamometer settings for each participant were recorded during the familiarization session and were used throughout the study. Volunteers were asked to cross their arms across the chest and to maximally contract their right knee extensors for $4 \mathrm{~s}$. They had two attempts to achieve their maximal isometric torque with 1-min of rest between attempts. Subjects also received verbal encouragement throughout the tests and all testing procedures were conducted by the same examiner.

\section{Muscle performance}

CMJ height was used as a measure of maximal muscle power and was measured on an AMTI force plate (model BP400600-HF-2000; Advanced Mechanical Technology, Inc., Watertown, MA, USA) with a sampling rate of $1000 \mathrm{~Hz}$. Since this test requires a SSC, it provides a more functional measurement of the muscle function $[3,20]$. The volunteers were asked to keep their hands on their hips and jump as high as possible. They had three attempts to achieve their best jump performance with 1-min of rest. A self-determined range of motion was permitted and they received verbal encouragement by the same examiner. Data obtained during vertical jumps were 
captured from the manufacturer's software (AMTI Acquisition Software, v 4.2; Advanced Mechanical Technology, Inc.) and processed using a custom MATLAB code (v R2008a7, The MathWorks Inc., Natick, MA, USA). From the ground reaction force data, the displacement curve was calculated and then integrated to obtain the displacement of the center of mass at each instant of movement; the greatest vertical displacement was considered as the maximal jump height, which was used for further analysis.

\section{Delayed-onset muscle soreness}

Perceived muscle soreness of quadriceps muscles was assessed using a $10 \mathrm{~cm}$ visual analog scale. The scale ranged from "no soreness" (0) to severe soreness (10). Individuals rated their quadriceps soreness during two conditions: (1) immediately after maximally contracting their right knee extensors muscles for $4 \mathrm{~s}$, and (2) sit-to-stand: three consecutive sit-to-stand movements from a 43-cm chair, which were performed with constant cadence (2 sec to sit and $2 \mathrm{sec}$ to stand) [23].

\section{Serum creatine kinase}

Blood was taken from the antecubital vein by a standard venipuncture technique using a commercially produced vacuum-sealed kit. After allowing $30 \mathrm{~min}$ for clotting, the collected blood was centrifuged at $2500 \mathrm{rpm}$ for $20 \mathrm{~min}$ at room temperature. The serum was aliquoted $(250 \mu \mathrm{L})$ and stored at $-20^{\circ} \mathrm{C}$ until analysis ( $<6$ months). Serum CK activity was analyzed with an enzymatic method at $37{ }^{\circ} \mathrm{C}$ using a test kit with limit of detection of zero (U/L) and linearity of the measurement of 1300 U/L (Total CK, Siemens Medical Systems, Germany). 
Thermal comfort was rated on a five-point Likert numerical scale where "0" was comfortable and "4" was extremely uncomfortable. Thermal sensation was rated on a nine-point Likert numerical scale where "-4" was very cold and "+4” was very hot [4]. Individuals were asked to rate the thermal comfort and thermal sensation before and every $5 \mathrm{~min}$ throughout the $20 \mathrm{~min}$ of CWI procedure.

\section{Skin temperature}

Before and every 5 min throughout the 20 min of CWI the thigh temperature was measured in a previously marked spot (central anterior) with a perpendicularly positioned infrared thermometer (Fluke, 566, China) that was kept as close as possible to the skin without touching. The participants stood up and their right leg was quickly and carefully dried without friction to measure the temperature, which took $\sim 15$ s to be completed.

\section{Statistical analysis}

The Shapiro-Wilks test was used to analyze data distribution. Box-plot graphs were created to allow the visual inspection in order to identify possible outliers. Muscle strength, muscle performance, and CK data (after log transformation) were normally distributed and therefore described as means and standard errors. DOMS data did not show a normal distribution, so it has been reported as median and interquartile ranges. Normally-distributed data were analyzed using a mixed-model ANOVA. When necessary, the degrees of freedom and F-values were corrected using the Greenhouse and Geisser method. A Kruskal-Wallis test was used to determine possible between-group differences for DOMS data, whereas a Mann-Whitney test was used to compare thermal sensation, thermal comfort, and skin temperature. SPSS (Statistical Package for Social 
Sciences) version 23.0 (IBM, USA) was used for statistical analysis with an alpha level set at 5\%. Retrospective statistical power (1- $\beta$ ) was calculated using $G^{*}$ Power software (version 3.1.2).

\section{Results}

\section{Physical characteristics of the participants}

Participants were randomly placed (using a random number table) into one of three groups: G5, G15 and GC. Age, body mass, height, percentage body fat, thigh skin fold, knee extensor torque, and CMJ height were not different between groups at baseline ( $\mathrm{P}>0.05$; Table 1$)$.

\section{Muscle Strength}

Isometric knee extensor peak torques at $60^{\circ}$ are presented in Figure 2. The exercise protocol reduced knee extensor torque $[(\mathrm{F} 3.77,147.11)=87.70, \mathrm{p}=0.001, f=0.18]$, which was mainly observed immediately post-exercise $(66.5 \pm 13.8 \%$ from pre-exercise). The torque gradually returned toward pre-exercise values, which only completely occurred $168 \mathrm{~h}$ post-exercise. There was no difference among the experimental groups $[F(7.54,147.11)=0.64, p=0.73$, power $(1-\beta)$ $=0.28]$.

\section{Muscle Performance}

CMJ performances are presented in Figure 3. Damaging exercise reduced jump performance $[(\mathrm{F} 3.25,81.23)=11.08, \mathrm{p}=0.001, f=0.31]$. The immediate decrements in performance $(84.1 \%-87.7 \% \pm 9.5 \%)$ were similar among the experimental groups, but they recovered differently between days. G5 and GC had a secondary drop in performance $48 \mathrm{~h}$ postexercise, whereas G15 showed a linear performance recovery. G15 then showed values near to 
baseline $72 \mathrm{~h}$ post-exercise $(\mathrm{p}=0.11$ ), and G5 group was no longer different to baseline at $96 \mathrm{~h}$ post-exercise $(\mathrm{p}=0.28)$. GC did not recover at any time point investigated $(\mathrm{p}<0.05)$.

\section{Delayed-onset muscle soreness}

Perceived muscle soreness during the seat-to-stand and maximal voluntary knee extension tasks are presented in Figure 4. Muscle soreness gradually increased, reaching maximum values at $48 \mathrm{~h}$ post-exercise. Although there were no differences between the experimental groups at any time point $(\mathrm{p}>0.05), \mathrm{G} 15$ tended to result in less soreness $24 \mathrm{~h}$ post-exercise. The median muscle soreness at $24 \mathrm{~h}$ measured during the seat-to-stand task was rated in 4.6 for G15 versus 5.8 for GC $(\mathrm{p}=0.07)$. During contraction it was rated 3.3 versus 4.9 for G15 and GC, respectively $(\mathrm{p}=0.06)$.

\section{Creatine Kinase}

Serum CK activity is presented in Figure 5. Damaging exercise increased serum CK concentration $[(\mathrm{F} 2.19,63.48)=40.62, \mathrm{p}=0.001, f=0.33]$ in the days following exercise. However, G15 CK levels were near to pre-exercise values $(\mathrm{p}=0.24)$ at $72 \mathrm{~h}$ post-exercise, whereas CK in G5 and GC did not return to baseline at any time point measured $(\mathrm{p}<0.05)$.

\section{Thermal comfort, thermal sensation and skin temperature}

Thermal comfort, thermal sensation and thigh skin temperature from CWI groups are presented in Figure 6. Baseline skin temperatures for each CWI group were similar before treatment $(\mathrm{p}=0.25)$. While both CWI groups demonstrated a significant reduction in skin temperature over time $(\mathrm{p}<0.001)$, those from G5 demonstrated lower skin temperature $(\mathrm{p}=0.001)$. Individuals from G5 reported lower thermal comfort at $5 \mathrm{~min}(\mathrm{p}<0.001)$ and at $10 \mathrm{~min}(\mathrm{p}=0.04)$, and they reported lower thermal sensation only at 5 min post-immersion $(p=0.01)$. 


\section{Discussion}

The main findings of the present study were that both CWI protocols were effective at accelerating CMJ recovery from damaging eccentric exercise, but not the isometric strength loss. This is a clear divergence between the impact of CWI on maximal contractile strength (which is commonly used as an indicator of 'muscle damage') and SSC performance. Furthermore, we had hypothesized that the colder $\left(5^{\circ} \mathrm{C}\right)$ intervention would produce better outcomes $[16,17]$; however, $\mathrm{CWI}$ at $15^{\circ} \mathrm{C}$ provided a superior benefit in $\mathrm{CMJ}$ recovery than at $5^{\circ} \mathrm{C}$. $\mathrm{G} 15$ recovered $\mathrm{CMJ}$ performance linearly overtime, whereas G5 and GC demonstrated a further decline in performance $48 \mathrm{~h}$ post-exercise. Individuals from G15 demonstrated a better recovery profile for CK response to damaging exercise, and showed no difference from baseline at $72 \mathrm{~h}$ post-exercise.

An important finding of the present study was that CWI accelerated CMJ performance recovery but not isometric strength recovery. Several studies have examined the effects of different CWI protocols on the time-course of recovery of muscle function from damaging exercise. Some studies have demonstrated a benefit of CWI on muscle function recovery [11, 24, 26, 28], but others did not $[6,9,23]$. This inconsistency appears to be partially related to the way in which the muscle function was evaluated. Those studies showing no benefit of CWI only measured knee extensor muscle function and assumed it to be as representative of muscle function, but it seems that isometric strength does not solely represent the overall muscle's capacity to produce work. Indeed, it has been suggested from a functional point of view that the ability for the whole myotendinous system to generate power is more important than isometric strength [3, 20]. CMJ performance, which is highly dependent on myotendinous capacity to generate power, seems to provide a better view of muscle function than isometric contraction. It has been pointed out that muscular prestretch activation, which takes place immediately before the propulsive phase of the CMJ, 
contributes to force development through a combination of several neuromuscular mechanisms, including (i) more time available to develop force, (ii) storage and reutilization of elastic energy, (iii) potentiation of contractile machinery, and (iv) activation of proprioceptive reflexes [3, 28]. Therefore, CWI application applied after damaging exercise may influence these aspects of SSC recovery to a greater extent than isometric strength recovery.

One of the most important advocated benefits of cryotherapy is the avoidance of secondary damage. One explanation for secondary damage is that the action of inflammatory cells may increase tissue damage through the activity of lysosomal enzymes degrading debris cells in addition to healthy tissue surrounding the primary damaged tissue [16]. Since cryotherapy has been largely associated with an attenuated inflammatory response [16, 27] and oxidative damage [22], its therapeutic effect should better control an exacerbated inflammatory action. This should theoretically translate into a smaller damaged area requiring a shorter recovery time.

It is a general assumption that the protocol with greater cooling capacity, such as CWI at 5 ${ }^{\circ} \mathrm{C}$, would facilitate restoration of performance better than a warmer protocol at $15^{\circ} \mathrm{C}[16,17]$. Nevertheless, recovery of CMJ performance and CK concentration were more rapid, and muscle soreness was less, at $24 \mathrm{~h}$ in G15 than G5. One possible explanation is that a complex stress was induced by the colder water. Lee et al. [13] and White et al. [28] found that CWI protocols of greater cooling capacity (longer duration or colder water) may actually exacerbate the proinflammatory response. Indeed, Tseng et al. [25] reported detrimental effects on recovery from damaging exercise when multiple applications of ice packs (temperature close to $0{ }^{\circ} \mathrm{C}$ ) were applied. Moreover, the different muscle function recovery pattern demonstrated between groups seems to indicate a positive effect of CWI applied at $15^{\circ} \mathrm{C}$. The $\mathrm{CMJ}$ recovery from G5 and GC demonstrated a bimodal pattern. The CMJ performance from these groups declined immediately 
following exercise, then declined further to reach their lowest values $48 \mathrm{~h}$ post-exercise. Although G5 demonstrated a quicker recovery than GC, the secondary decline in CMJ performance suggests it might be associated with an exacerbated inflammatory response [3], and this might be explicitly examined in future research.

Although the ability to reduce muscle soreness has been often attributed to cold therapies $[2,8,14]$, there are still uncertainties in this regard. In the present study, we only observed a trend towards lower muscle soreness $24 \mathrm{~h}$ post-exercise. The lack of a substantial effect in the current investigation might be explained by the fact that we used a single CWI application in both CWI groups. Also, a highly inter-individual variability in DOMS response would have masked any significant statistical difference between groups. Bleakley et al [2] suggested that differences in muscle soreness of $13 \%$ to $22 \%$ can be considered clinically meaningful. In the current study the difference in muscle soreness was 39\% (3.3 vs 4.9) and 16\% (4.6 vs 5.8) between G15 and GC 24 $\mathrm{h}$ post-exercise, which demonstrates the potential clinical benefit of CWI at $15^{\circ} \mathrm{C} 24 \mathrm{~h}$ during the first 24 h post-exercise. Skurvydas et al. [24] showed that CWI at $15^{\circ} \mathrm{C}$ significantly attenuated DOMS following damaging exercise. They applied CWI at multiple times $(0,4,8,24 \mathrm{~h})$ using a relatively longer duration ( 2 bouts of 15-min). They also used a crossover study design, which reduces inter-individual variability. While crossover design in this particular situation is not recommended due to repeated bout effect, the effect of single versus multiple applications warrants future investigation.

A limitation of the present study was that direct measurement of inflammatory markers was not included. Although changes in force-generating capacity provide a robust and reliable indication of the muscle's status [21], the examination of either local or systemic inflammatory responses might provide additional valuable information. This would improve our understanding of the potential modulatory effect of water temperature on muscle regeneration after EIMD. 
Another aspect to be considered was the inclusion only of young, healthy males who do not perform structured sports training in the current investigation, which delimits our results to this population. Further examination in other populations is thus warranted.

In conclusion, this investigation addressed the limitations described in previous studies in which the choice of water temperature has been made based on anecdotal experience [14]. While both CWI protocols were associated with an improved time course of CMJ recovery, with better outcomes in favor of $15^{\circ} \mathrm{C}$, no benefit of CWI on isometric recovery was found. This discrepancy suggests that CWI might enhance aspects of SSC recovery, such as utilization of elastic energy for muscular structures, activating proprioceptive reflexes, increasing the time to produce force and/or force potentiation. Furthermore, the reported controversy $[6,9,11,23,24,26,28]$ about the effects of CWI on muscle function recovery might be due to the way in which muscle function has been measured following damaging exercises. From a practical stand point, CWI appears to be more effective at restoring muscle function during activities incorporating SSC than restoring isometric strength. However, the mechanisms underlying the effects of cooling on improving the stretchshortening capabilities of the muscle warrants further investigation.

\section{References}

1. ACSM. ACSM's Guidelines for Exercise Testing and Prescription. 8th ed. Chicago: Lippincott Williams \& Wilkins; 2010

2. Bleakley C, McDonough S, Gardner E, Baxter GD, Hopkins JT, Davison GW. Cold-water immersion (cryotherapy) for preventing and treating muscle soreness after exercise. Cochrane Database Syst Rev 2012; 2: CD008262

3. Byrne C, Twist C, Eston R. Neuromuscular function after exercise-induced muscle damage: theoretical and applied implications. Sports Med 2004; 34: 49-69

4. Costello JT, Culligan K, Selfe J, Donnelly AE. Muscle, skin and core temperature after 110 degrees c cold air and 8 degrees c water treatment. PLoS One 2012; 7: e48190 
5. Ferreira-Junior JB, Bottaro M, Vieira A, Siqueira AF, Vieira CA, Durigan JL, Cadore EL, Coelho LG, Simoes HG, Bemben MG. One session of partial-body cryotherapy (-110 degrees C) improves muscle damage recovery. Scand J Med Sci Sports 2015; 25: e524-530

6. Goodall S, Howatson G. The effects of multiple cold water immersions on indices of muscle damage. J Sport Sci Med 2008; 7: 235-241

7. Harriss DJ, Atkinson G. Ethical Standards in Sport and Exercise Science Research: 2016 Update. Int J Sports Med 2015; 36: 1121-1124

8. Hohenauer E, Taeymans J, Baeyens JP, Clarys P, Clijsen R. The Effect of Post-Exercise Cryotherapy on Recovery Characteristics: A Systematic Review and Meta-Analysis. PLoS One 2015; 10: e0139028

9. Jakeman JR, Macrae R, Eston R. A single 10-min bout of cold-water immersion therapy after strenuous plyometric exercise has no beneficial effect on recovery from the symptoms of exercise-induced muscle damage. Ergonomics 2009; 52: 456-460

10. Kennet J, Hardaker N, Hobbs S, Selfe J. Cooling efficiency of 4 common cryotherapeutic agents. J Athl Train 2007; 42: 343-348

11. King M, Duffield R. The effects of recovery interventions on consecutive days of intermittent sprint exercise. J Strength Cond Res 2009; 23: 1795-1802

12. Koch AJ, Pereira R, Machado M. The creatine kinase response to resistance exercise. J Musculoskelet Neuronal Interact 2014; 14: 68-77

13. Lee EC, Watson G, Casa D, Armstrong LE, Kraemer W, Vingren JL, Spiering BA, Maresh CM. Interleukin- 6 responses to water immersion therapy after acute exercise heat stress: a pilot investigation. J Athl Train 2012; 47: 655-663

14. Leeder J, Gissane C, van Someren K, Gregson W, Howatson G. Cold water immersion and recovery from strenuous exercise: a meta-analysis. Br J Sports Med 2012; 46: 233-240

15. Machado M, Willardson JM. Short recovery augments magnitude of muscle damage in high responders. Med Sci Sports Exerc 2010; 42: 1370-1374

16. Merrick MA. Secondary injury after musculoskeletal trauma: a review and update. J Athl Train 2002; 37: 209-217

17. Merrick MA, Jutte LS, Smith ME. Cold Modalities With Different Thermodynamic Properties Produce Different Surface and Intramuscular Temperatures. J Athl Train 2003; 38: 28-33 
18. Miyama M, Nosaka K. Influence of surface on muscle damage and soreness induced by consecutive drop jumps. J Strength Cond Res 2004; 18: 206-211

19. Miyama M, Nosaka K. Protection against muscle damage following fifty drop jumps conferred by ten drop jumps. J Strength Cond Res 2007; 21: 1087-1092

20. Nicol C, Avela J, Komi PV. The stretch-shortening cycle : a model to study naturally occurring neuromuscular fatigue. Sports Med 2006; 36: 977-999

21. Paulsen G, Mikkelsen UR, Raastad T, Peake JM. Leucocytes, cytokines and satellite cells: what role do they play in muscle damage and regeneration following eccentric exercise? Exerc Immunol Rev 2012; 18: 42-97

22. Puntel GO, Carvalho NR, Amaral GP, Lobato LD, Silveira SO, Daubermann MF, Barbosa NV, Rocha JB, Soares FA. Therapeutic cold: An effective kind to modulate the oxidative damage resulting of a skeletal muscle contusion. Free Radic Res 2011; 45: 125-138

23. Sellwood KL, Brukner P, Williams D, Nicol A, Hinman R. Ice-water immersion and delayed-onset muscle soreness: a randomised controlled trial. Br J Sports Med 2007; 41: 392-397

24. Skurvydas A, Sipaviciene S, Krutulyte G, Gailiuniene A, Stasiulis A, Mamkus G, Stanislovaitis A. Cooling leg muscles affects dynamics of indirect indicators of skeletal muscle damage. J Back Musculoskeletal 2006; 19: 141-151

25. Tseng CY, Lee JP, Tsai YS, Lee SD, Kao CL, Liu TC, Lai C, Harris MB, Kuo CH. Topical cooling (icing) delays recovery from eccentric exercise-induced muscle damage. J Strength Cond Res 2013; 27: 1354-1361

26. Vaile J, Halson S, Gill N, Dawson B. Effect of cold water immersion on repeat cycling performance and thermoregulation in the heat. J Sports Sci 2008; 26: 431-440

27. Vieira Ramos G, Pinheiro CM, Messa SP, Delfino GB, Marqueti Rde C, Salvini Tde F, Durigan JL. Cryotherapy Reduces Inflammatory Response Without Altering Muscle Regeneration Process and Extracellular Matrix Remodeling of Rat Muscle. Sci Rep 2016; 6: 18525

28. White GE, Rhind SG, Wells GD. The effect of various cold-water immersion protocols on exercise-induced inflammatory response and functional recovery from high-intensity sprint exercise. Eur J Appl Physiol 2014; 114: 2353-2367

29. Wilcock IM, Cronin JB, Hing WA. Physiological response to water immersion: a method for sport recovery? Sports Med 2006; 36: 747-765 


\section{Figure Legends}

Figure 1. Experimental design of the study. The time when each outcome were assessed are presented. MVIC: Maximal Voluntary Isometric Contraction; CMJ: Countermovement Jump; CK: Creatine Kinase; DOMS: Delayed onset Muscle Soreness; EIMD: Exercise-induced muscle damage; G5: cold water immersion (CWI) at $5^{\circ} \mathrm{C}$; G15: CWI at $15^{\circ} \mathrm{C}$; GC: control group.

Figure 2. Changes (mean \pm SEM) in knee extensor torque from baseline (Pre), at immediately after (Post), from $24 \mathrm{~h}$ to $96 \mathrm{~h}$, and $168 \mathrm{~h}$ post-exercise. Cold water immersion (CWI) at $15^{\circ} \mathrm{C}(\bullet)$; CWI at $15{ }^{\circ} \mathrm{C}(\mathrm{\circ})$; and control group ( $\left.\mathbf{a}\right)$. ${ }^{\mathrm{a}}$ means different from baseline for $\mathrm{CWI}$ at $15{ }^{\circ} \mathrm{C}$; ${ }^{\mathrm{b}}$ means different from baseline for $\mathrm{CWI}$ at $5^{\circ} \mathrm{C}$; ${ }^{\mathrm{c}}$ means different from baseline for control group.

Figure 3. Changes (mean $\pm \mathrm{SEM}$ ) in counter movement jump (CMJ) performance from baseline (Pre), at immediately after (Post), from $24 \mathrm{~h}$ to $96 \mathrm{~h}$, and $168 \mathrm{~h}$ post-exercise. Cold water immersion (CWI) at $15{ }^{\circ} \mathrm{C}(\bullet)$; CWI at $15{ }^{\circ} \mathrm{C}(\mathrm{O})$; and control group (匹). ${ }^{\mathrm{a}}$ means different from baseline for CWI at $15{ }^{\circ} \mathrm{C}$; ${ }^{b}$ means different from baseline for CWI at $5{ }^{\circ} \mathrm{C}$; ${ }^{c}$ means different from baseline for control group.

Figure 4. Changes (median \pm interquartile range) in perceived muscle soreness during seat-to-stand (A) and maximal voluntary contraction (MVC; B) at baseline (Pre), immediately after (Post), from $24 \mathrm{~h}$ to $96 \mathrm{~h}$, and $168 \mathrm{~h}$ post-exercise. Cold water immersion (CWI) at $15^{\circ} \mathrm{C}(\bullet)$; $\mathrm{CWI}$ at $15^{\circ} \mathrm{C} \mathrm{(o)}$; and control group ( $\mathbf{a}){ }^{\mathrm{a}}$ means different from baseline for CWI at $15^{\circ} \mathrm{C}$; ${ }^{\mathrm{b}}$ means different from baseline for $\mathrm{CWI}$ at $5{ }^{\circ} \mathrm{C}$; ${ }^{\mathrm{c}}$ means different from baseline for control group. 
Figure 5. Serum creatine kinase (CK) activity (mean \pm SEM) from baseline (Pre), one day to three days (D1-D3), from 24h to $96 \mathrm{~h}$, and $168 \mathrm{~h}$ post-exercise. Cold water immersion (CWI) at $15^{\circ} \mathrm{C}(\bullet)$; CWI at $15^{\circ} \mathrm{C}(\mathrm{O})$; and control group (a). ${ }^{\mathrm{a}}$ means different from baseline for $\mathrm{CWI}$ at $15^{\circ} \mathrm{C} ;{ }^{\mathrm{b}}$ means different from baseline for $\mathrm{CWI}$ at $5^{\circ} \mathrm{C}$; ${ }^{\mathrm{c}}$ means different from baseline for control group.

Figure 6. Skin temperature, thermal comfort and thermal sensation measured before and every 5 min throughout the 20 minutes of CWI procedure. Cold water immersion $(\mathrm{CWI})$ at $5{ }^{\circ} \mathrm{C}(\mathrm{O})$; $\mathrm{CWI}$ at $15^{\circ} \mathrm{C}(\bullet)$. *means difference between groups.
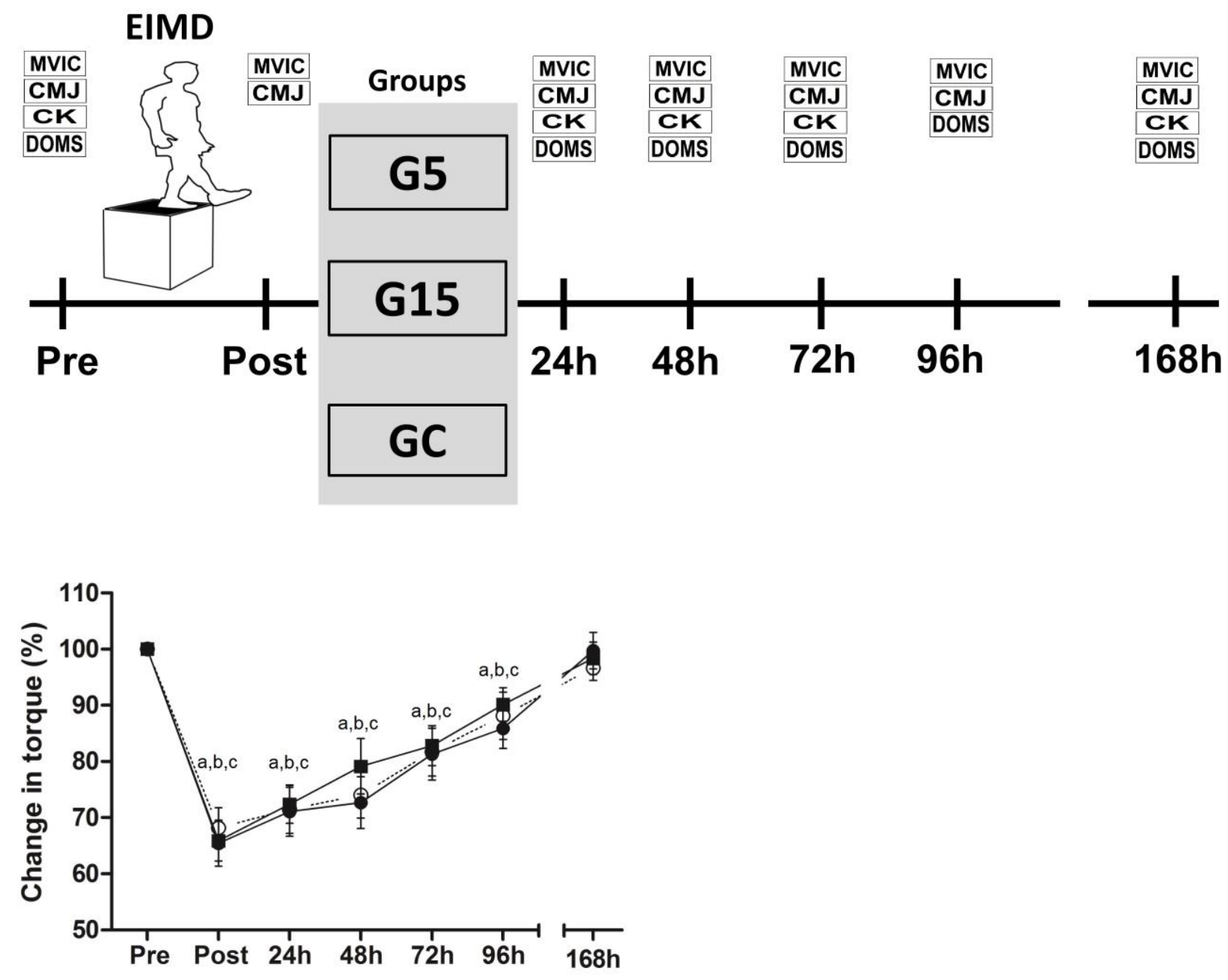

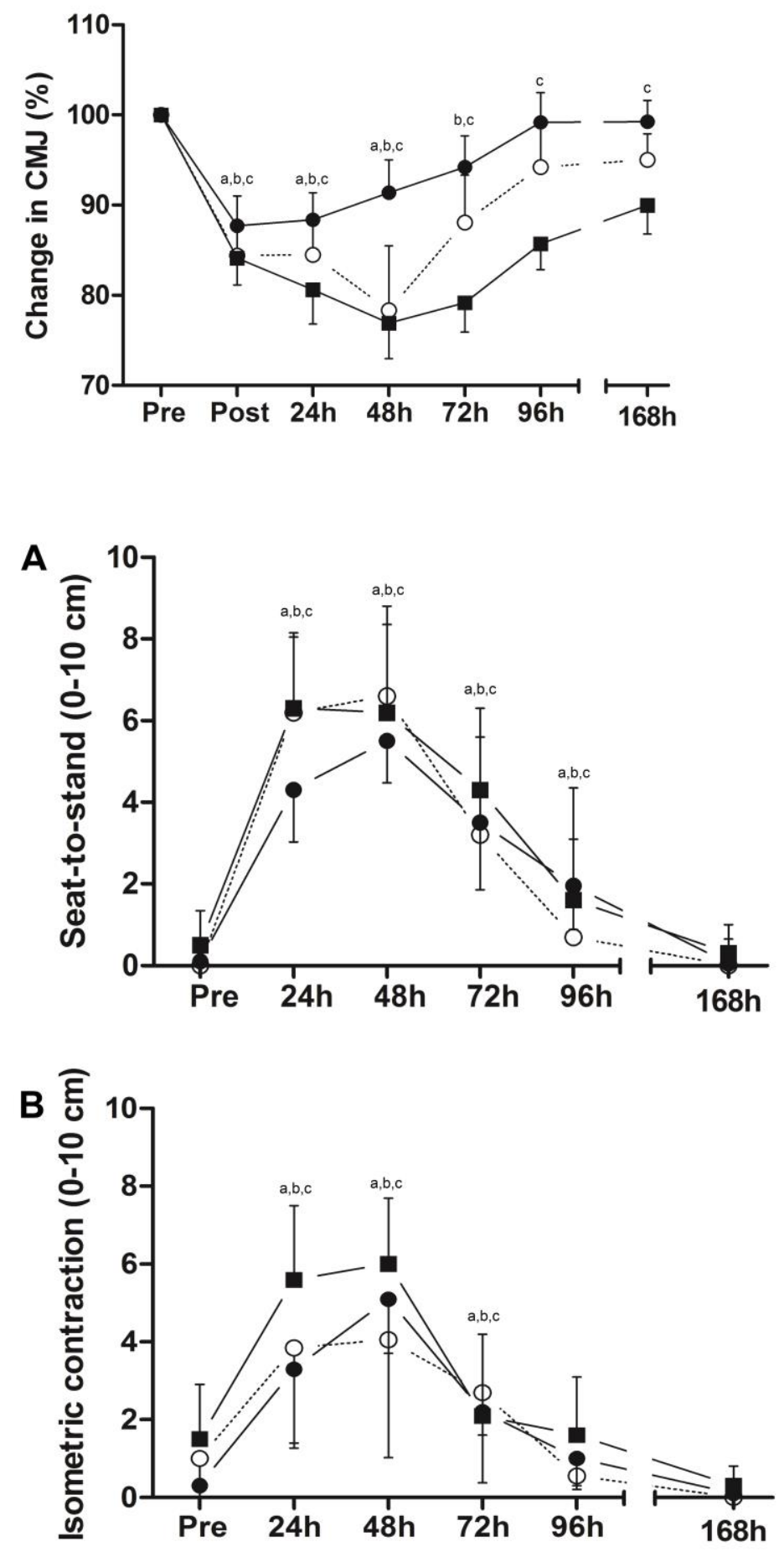


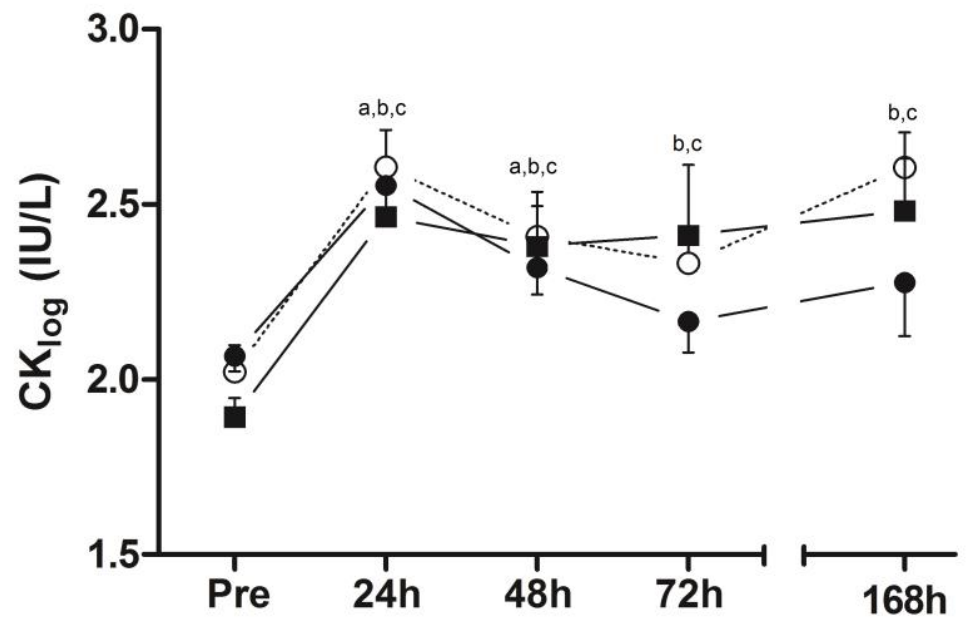




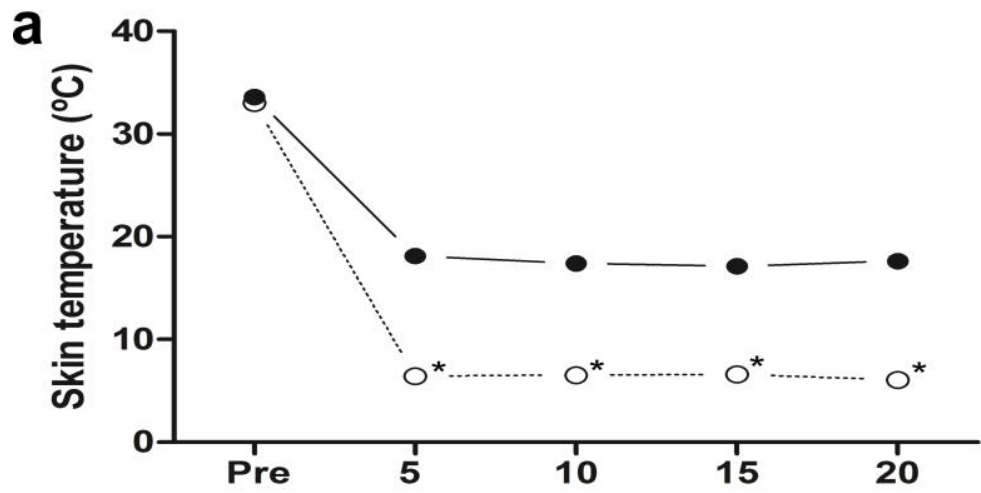

b
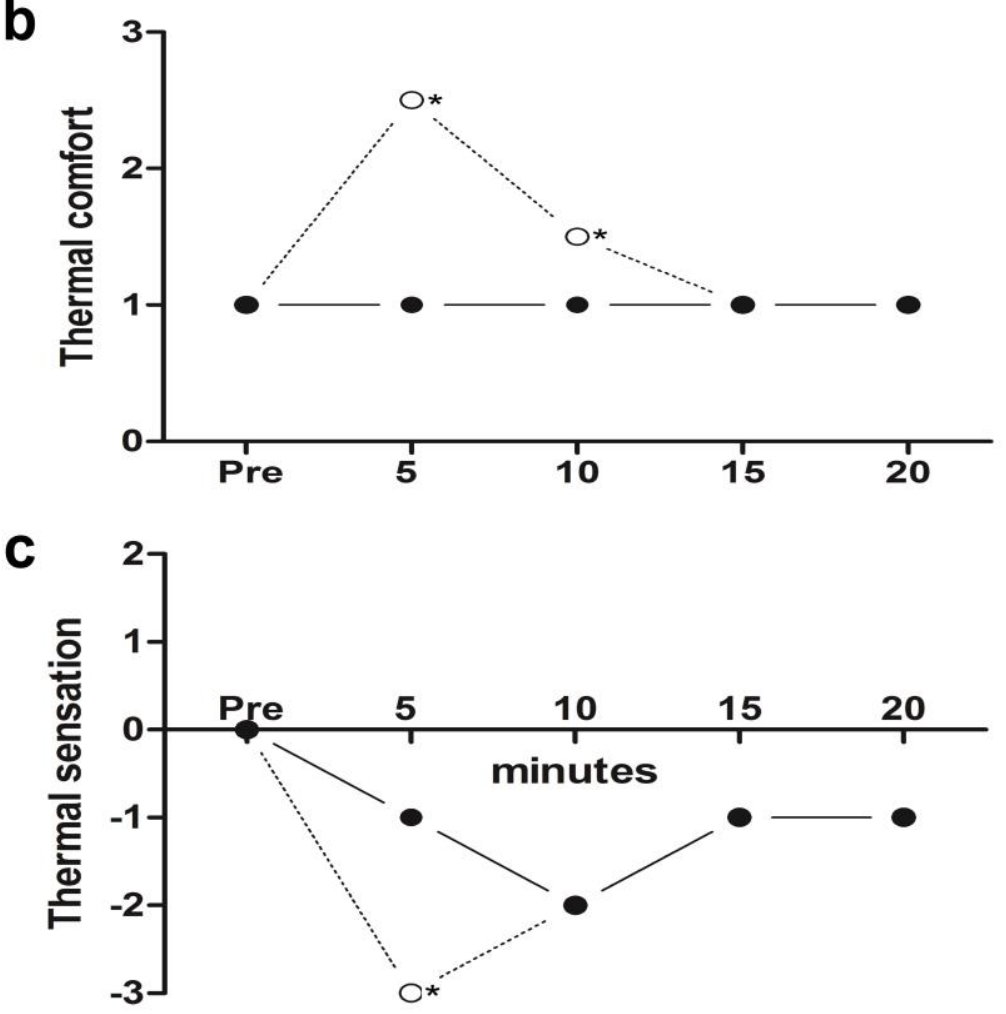